LAILA MASSAD

\title{
Desempenho diagnóstico e mapeamento cognitivo cerebral de radiologistas veterinários através de um sistema computacional
}

Dissertação apresentada à Faculdade de Medicina da Universidade de São Paulo para obtenção de título de Mestre em Ciências

Área de concentração: Fisiopatologia Experimental Orientador: Prof. Dr. Armando Freitas da Rocha

\section{São Paulo 2008}


Dedico este trabalho ao meu pai, Eduardo, que foi quem mais me ajudou e que me serviu de grande exemplo, não só agora como por toda minha vida. 


\section{AGRADECIMENTOS}

A todos aqueles de fundamental importância na realização de cada etapa deste trabalho, meus agradecimentos:

Ao Prof. Dr. Armando Freitas da Rocha por toda atenção e dedicação, além da grande oportunidade que me foi oferecida.

À Profa. Dra. Neli Ortega pelo carinho com que me ajudou na avaliação dos resultados, sempre disposta e atenciosa.

Ao Fábio Rocha pela presença fundamental durante o trabalho de campo e pela paciência nos esclarecimentos de minhas dúvidas.

Ao Prof. Milton Kolber que carinhosamente me ofereceu as imagens e que foi fundamental em minha formação acadêmica.

À Profa. Gabriela Rodrigues que participou ativamente na elaboração das tarefas, sempre atenciosa e disposta a me ajudar.

Aos colegas voluntários que participaram com muita boa vontade das tarefas e que, na ausência destes, o trabalho não poderia ter sido realizado. 
À minha mãe, Mara, que, como uma boa mãe e colega, opinou em cada detalhe do estudo e me deu todo o apoio durante as etapas mais difíceis.

Ao meu pai, Prof. Dr. Eduardo Massad, que me serviu de inspiração e que, sem dúvidas, foi quem mais me ajudou.

A minha querida professora de inglês, Adriana Toujeiro, que me acompanhou e ajudou muito desde a prova de seleção até a qualificação.

Ao meu marido, Carlos, por toda a paciência e presença fundamental durante minhas crises e também pela enorme ajuda na parte de informática. 
Resumo

\section{SUMÁRIO}

Summary

1 INTRODUÇÃO

Erro! Indicador não definido.

2 REVISÃO DE LITERATURA ............................Erro! Indicador não definido.

2.1. O processo de Tomada de Decisão em Radiologia .. Erro! Indicador não definido.

2.2. História do Eletroencefalograma

2.3. História da Radiologia

2.4. O Cérebro.

Erro! Indicador não definido.

2.4.1. A Visão

Erro! Indicador não definido.

2.4.2. A Memória

Erro! Indicador não definido.

2.5. Métodos de Mapeamento Cerebral Erro! Indicador não definido.

2.6. O Sistema Computacional. Erro! Indicador não definido.

2.7. Diferenciação entre Gêneros. Erro! Indicador não definido.

3 OBJETIVOS Erro! Indicador não definido.

3.1. Geral. Erro! Indicador não definido.

3.2. Específicos Erro! Indicador não definido.

4 MATERIAIS E MÉTODOS Erro! Indicador não definido.

5 RESULTADOS Erro! Indicador não definido.

6 DISCUSSÃO Erro! Indicador não definido.

7 CONCLUSÕES Erro! Indicador não definido.

8 BIBLIOGRAFIA Erro! Indicador não definido. Erro! Indicador não definido. 
Resumo

Massad, L. Desempenho diagnóstico e mapeamento cognitivo cerebral de radiologistas veterinários através de um sistema computacional [dissertação]. São Paulo: Faculdade de Medicina, Universidade de São Paulo; 2008. $73 p$

Com intuito de avaliar o processo cognitivo cerebral e o desempenho de médicos veterinários especializados em radiologia, este estudo proporcionou, através de um sistema computacional, tarefas de questões radiológicas. Os 29 voluntários foram divididos por gênero: homens $(n=13)$ e mulheres $(n=16)$; e por tempo de especialidade: iniciantes $(n=13)$, experientes $(n=8)$ e seniores $(n=8)$. Quatorze casos foram selecionados com diferentes níveis de dificuldade a partir de imagens radiográficas de cães e gatos e foram escaneadas e colocadas em um programa chamado $E n s c e r^{\circledR}$, adaptado para a realização deste estudo. Os casos eram divididos em três partes, nomeadas, história clínica, imagem radiográfica e decisão diagnóstica. Durante as etapas, foram realizados eletroencefalogramas dos voluntários, que resultaram em mapeamentos cerebrais. Além disso, foi feita avaliação das respostas corretas, incorretas e dos tempos utilizados para as tarefas. Através das avaliações estatísticas dos resultados foi possível concluir que radiologistas veterinários com maior tempo de especialidade foram estatisticamente mais rápidos nas tarefas e tiveram melhor desempenho diagnóstico; voluntários com maior tempo de especialidade ativaram áreas cerebrais diferentes dos menos experientes; o desempenho diagnóstico foi quantitativamente igual em voluntários de ambos os gêneros e o mapeamento cerebral do grupo masculino foi diferente do grupo feminino, mesmo com desempenho igual nas atividades.

Descritores: 1. Mapeamento encefálico 2. Eletroencefalografia 3. Radiologia 
Summary

Massad, L. Veterinarian radiologists' performance and cognitive brain map through a computerized system. [dissertation]. São Paulo: College of Medicine, University of São Paulo; 2008. 73p

With intention to evaluate the cerebral cognitive process and the performance of medical veterinarians specialized in radiology, this study provided, through a computerized system, tasks of radiological questions. The 29 volunteers were divided by gender: man $(n=13)$ and woman $(n=16)$; and by time of experience: beginners $(n=13)$, experienced $(n=8)$ and seniors $(n=8)$. Fourteen cases were selected with different levels of difficulty from radiographic images of dogs and cats and had been scanned and processed by a software called Enscer $\circledast$, adapted for the accomplishment of this study. The cases were divided into three parts, namely, clinical history, radiographic image and diagnostic decision. During the stages the electroencephalography was carried through, which resulted in the cerebral mapping. Moreover, evaluation of the correct and incorrect answers and of the times used for the tasks was made. Through the statistical evaluations of the results it was possible to conclude that radiologists veterinarians with more time of experience had been statistically faster in the tasks and had had better diagnostic performance; volunteers with more time of experience had activated different cerebral areas than volunteer with less experience; the diagnostic performance was quantitatively equal in volunteers of both genders and the cerebral mapping of the masculine group was different of the feminine group, even with equal performance in the activities.

Descriptors: 1. Brain mapping 2. Electroencephalography 3. Radiology. 
1 INTRODUÇÃO 
A tomada de decisão é um processo para sistematicamente analisar escolhas complexas (SMITH e SLENNING, 2000; PAULUS, 2007; KORDIN, 2007) considerando todas as informações pertinentes (SMITH e SLENNING, 2000) e é flexível, fácil de entender e importante na ajuda em situações aonde os resultados não podem ser previstos com certeza (NGATEGIZE et al, 1986). Segundo KOECHIL e HYAFIL (2007) a tomada de decisão é o reino do lobo frontal, abrangendo desde uma simples escolha, como escolher uma maçã em uma fruteira, até a mais complexa, como o próximo movimento em um jogo de xadrez.

Os métodos de mapeamento cerebral têm avançado rapidamente nas últimas décadas e esses métodos têm resultado em desenvolvimento no diagnóstico e monitoramento da terapêutica, além de promover idéias dos mecanismos básicos de desordens cerebrais (MAZZIOTA, 2000). A Eletroencefalografia, por exemplo, pode ser utilizada como teste de diagnóstico em uma série de indicações (FOWLE e BINNIE, 2000), como na detecção de epilepsias (BINNIE e PRIOR, 1994; MAZZIOTA, 2000).

Métodos de avaliação computacional têm sido considerados poderosos em promover serviços de avaliação psicológica. Os computadores, desde quando foram introduzidos e adaptados para avaliação psicológica na década 
de 1950, têm sido valiosos nas interpretações de testes e no processamento de dados (BUTCHER, PERRY e HAHN, 2004).

Apesar de todo o avanço tecnológico e do grande número de pesquisas relacionadas aos processamentos cerebrais, os processos cognitivos envolvidos no diagnóstico radiológico ainda não são conhecidos. Quais áreas cerebrais são ativadas ao longo de processo diagnóstico, em que seqüência estas áreas são ativadas, qual a diferença do desempenho entre gêneros e entre diferentes níveis de tempo de especialidade são algumas das questões ainda sem resposta. Contudo, ainda que de maneira preliminar, estas questões é a motivação desta dissertação, que tem como objetivo avaliar o processo cognitivo diagnóstico em amostra de médicos veterinários especializados em radiologia. 
2 REVISÃO DE LITERATURA 


\subsection{O processo de Tomada de Decisão em Radiologia}

A observação humana consiste em dois processos interrrelacionados quando ocorre interpretação de imagens médicas: percepção e análise. Percepção é definida como "consciência unificada de um conteúdo de uma imagem demonstrada que está presente enquanto há estímulo" (THE RANDOMHOUSE COLLEGE DICTIONARY, 1998). Análise determina o significado de percepção no contexto do problema médico que iniciou a aquisição da imagem (KUNDEL, 1979). No livro How Doctors Think, de Jerome Groopman, o radiologista Dennis Orwig define radiologia da mesma maneira, ou seja, como uma disciplina dividida em dois processos: percepção e cognição. Isso significa que um radiologista precisa primeiramente fazer uma observação e posteriormente analisar o que foi observado, o que significa e a possível explicação para o achado (GROOPMAN, 2007).

A radiologia diagnóstica é um importante componente da informação clínica em pacientes em tratamento e a informação é definida como uma redução da incerteza e a proposta de qualquer diagnóstico é diminuir incertezas clínicas (POTCHEN, 2006). Porém, radiologistas têm considerado a análise de imagens como sendo campo primário da pesquisa e têm ingenuamente assumido que o que é relatado na imagem é uma representação fiel da informação contida nas imagens e não têm se preocupado com o processo de percepção, até falharem (KUNDEL, 2006). 
Há algumas décadas um radiologista provavelmente avaliava entre doze e 15 mil casos por ano e estima-se que, atualmente, a carga de trabalho anual chega a 25 mil casos. Alguns casos geram poucas imagens, mas outras podem gerar centenas ou milhares, como no caso de tomografias computadorizadas. Por este motivo, os radiologistas precisam avaliar as imagens muito rapidamente (GROOPMAN, 2007). Um estudo com mais de 100 radiologistas foi realizado para avaliação de desempenho na avaliação de imagens radiográficas. No estudo foram utilizadas 60 radiografias de tórax com algumas imagens duplicadas. Quando perguntado ao radiologista se a imagem era normal, eles discordaram entre si em $20 \%$ das vezes. Isto é chamado "variabilidade interobservacional", ou seja, variação de opinião entre os observadores. Quando um único radiologista revia a mesma imagem em um outro dia, este contradizia sua primeira análise em 5 a $10 \%$ das vezes e isto é chamada "variabilidade intraobservacional" (GROOPMAN, 2007; POTCHEN, 2006; FREEDMAN e OSICKA, 2006), ou seja, variação de opinião de um único observador em diferentes momentos (GROOPMAN, 2007; POTCHEN, 2006). Além disso, foi realizada uma comparação entre os radiologistas entre os 20 melhores, que tiveram um desempenho de $95 \%$, com os 20 piores observadores, que tiveram um desempenho de $75 \%$. Concluiu-se que os piores radiologistas, além de estarem errados, estavam confiantes de que estavam certos, quando na verdade estavam errados. Com relação ao tempo de resposta dos voluntários, POTCHEN (2006) observou que, após 38 segundos olhando uma radiografia, muitos radiologistas começaram a ver sinais que não 
estavam na imagem, ou seja, se a avaliação da imagem for muito longa, aumentam as margens de erro. 


\subsection{História do Eletroencefalograma}

O primeiro estudo relacionado com eletricidade em seres vivos foi feito no final do século XVIII por Luigi Galvani, um fisiologista italiano que observou que pernas de rãs contraíam-se quando o nervo que se dirigia ao músculo era tocado por um fio de latão ou cobre que fazia contato ao um fio de ferro que, por sua vez fazia contado com o músculo (Figura 1). Galvani acreditava que existia uma "eletricidade animal" presente no tecido, mas Allesandro Volta, um físico, demonstrou que a corrente elétrica era produzida pelo contato dos dois metais desiguais, colocados num ambiente úmido ou líquido.

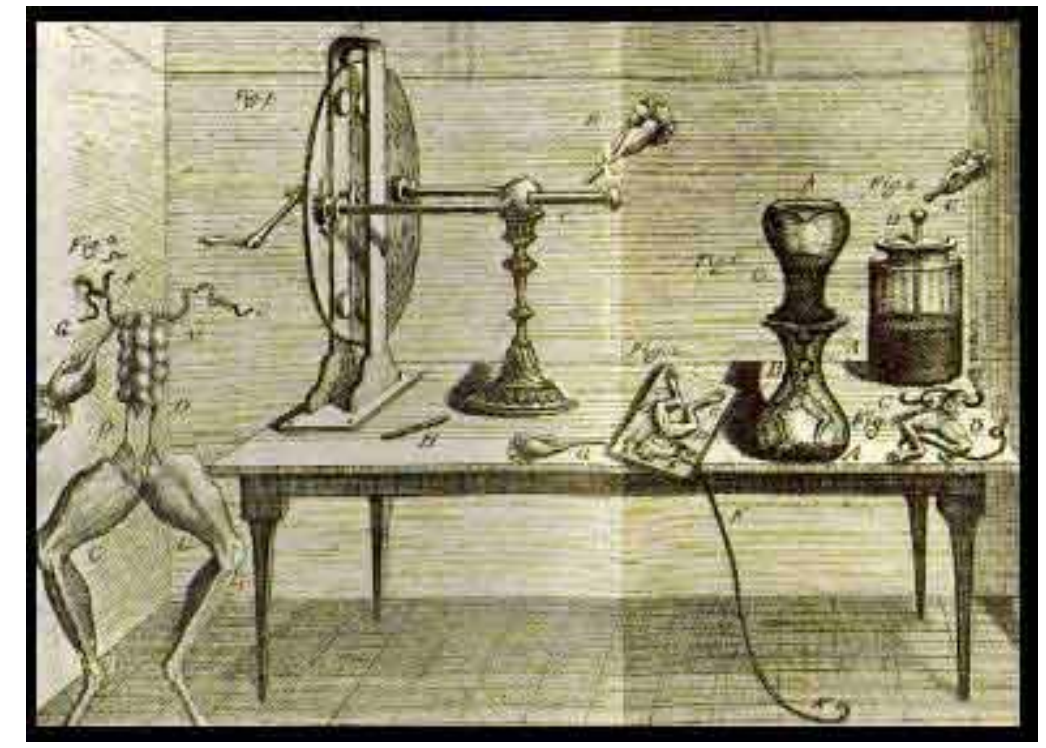

Figura 1. Laboratório de Luigi Galvani - 1971

(http://br.geocities.com/saladefisica9/biografias/galvani.htm)

Em 1848 foi demonstrado por Bois-Reymond, um fisiologista alemão, que ocorre um sinal elétrico concomitantemente à passagem de um impulso 
nervoso. A partir desse estudo, Richard Caton, um fisiologista britânico, relatou alguns estudos com macacos e coelhos, que demonstravam que existência de correntes elétricas muito fracas no cérebro dos animais.

Em 1929, Hans Berger, um neuropsiquiatra alemão, publicou seus estudos que demonstravam atividade elétrica no cérebro humano. Berger foi quem cunhou o termo eletroencefalograma ou EEG (Figura 2) (DUFFY, IYER e SURWILLO, 1999).
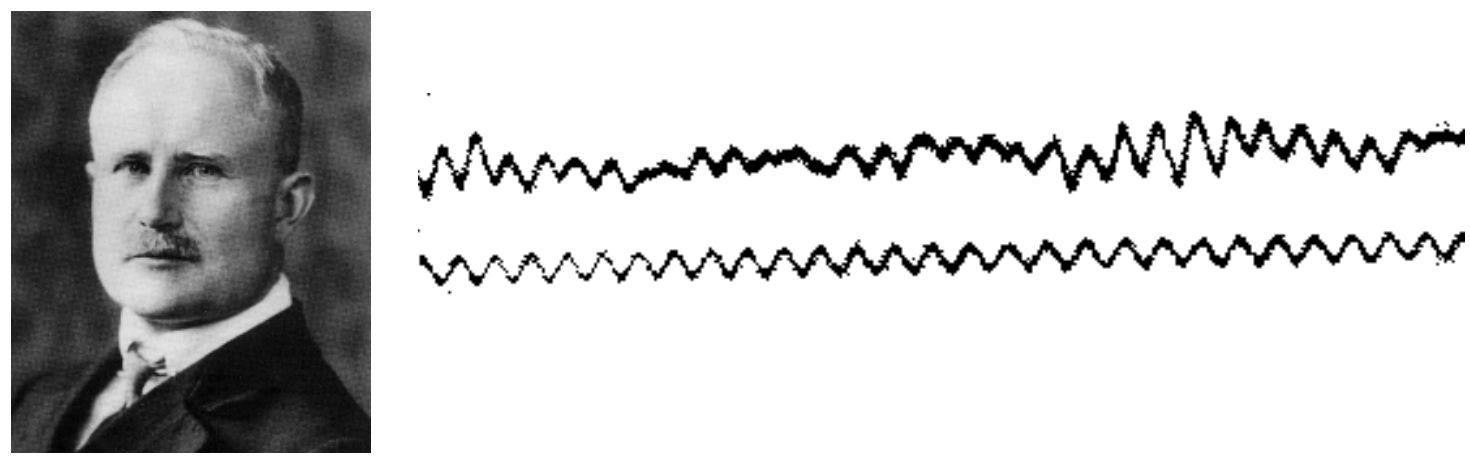
WANMNANNANMNMNMNM

Figura 2 - Hans Berger e o primeiro EEG registrado na história em 1929 (http:www.neurophysiologyreview.com/eeg.html) 


\subsection{História da Radiologia}

Em 1895 o físico Wilhelm Conrad Roentgen (1845-1923) descobriu o que denominou de raios $\mathrm{X}$ enquanto pesquisava o tubo de raios catódicos inventado pelo inglês William Crookes (1832-1919) anos antes. Roentgen fez a radiação atravessar por 15 minutos a mão de sua esposa Bertha, atingindo, do outro lado, uma chapa fotográfica, que quando revelada apresentou sombras dos ossos de Bertha (Figura 3). Experimentos realizados mais tarde demonstraram que os raios $X$ produzem uma imagem em um filme fotográfico e penetram muitos materiais como papel, madeira, alguns metais e tecidos vivos. Pela primeira vez os cientistas tinham uma ferramenta não cirúrgica que permitia ver dentro do corpo. Em 1901 Roentgen recebeu o prêmio Nobel de física (http://www.rad-i-ology.co.uk/radsite/historical.htm)
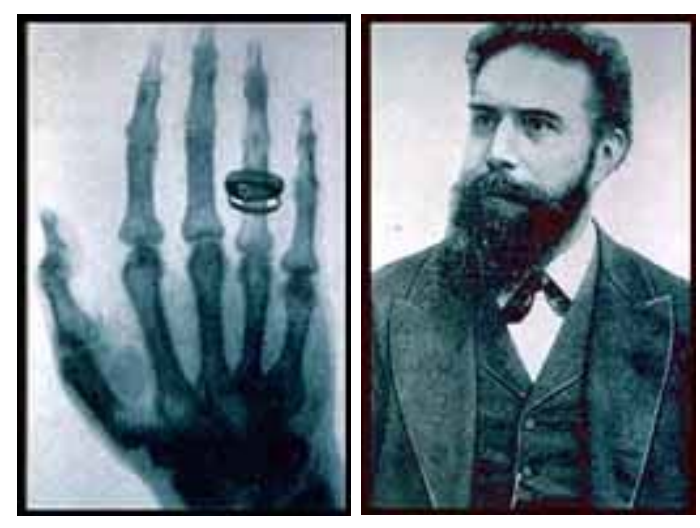

Figura 3 - Mão de Betha (primeira imagem radiográfica produzida) e Wilhelm Conrad Roentgen (http://www.rad-i-ology.co.uk/radsite/historical.htm) 
Após a descoberta dos raios $\mathrm{X}$, um dos maiores avanços na imagem foi a fluoroscopia. Descrita por um físico italiano três meses após a descoberta de Roetgen, a fluoroscopia consistia em um tubo com uma tela fluorescente de um lado e uma lente do outro. Uma parte do corpo ficava entre o tubo de raios $\mathrm{X}$ e a tela produzia uma imagem até mesmo em um ambiente iluminado. Um mês depois, Thomas Edson anunciou que o tungstato de cálcio fluoresceria mais que o platinocianato de bário. Na época acreditava-se que as imagens radiográficas não seriam mais necessárias devido à fluoroscopia, mas hoje em dia é sabido que isto não é verdade. Ambas as técnicas de imagens são fundamentais.

Em 1972 Godfrey Hounsfield, um engenheiro inglês inventou a Tomografia Computadorizada (TC), que combina imagens radiográficas com um computador. Se fossem realizados diversos raios $\mathrm{X}$ de uma mesma área, mas com ângulos minimamente diferentes, um computador conseguiria unir as informações vindas dos raios $X$ para criar uma imagem transversal. Os primeiros aparelhos de TC para uso clínico foram instalados em 1975.

O primeiro uso clínico da Imagem por Ressonância Magnética foi em 1967 no hospital da Universidade de Nottingham. As imagens ainda não tinham qualidade suficiente para serem usadas na medicina e, após muitos avanços no início da década de 1980, os cientistas se impressionaram com a visualização de anormalidades no cérebro. Atualmente a Ressonância Magnética é a técnica de imagem de escolha para a maior parte do corpo. 
O sistema de deteç̧ão de ultra-som em baixo da água foi desenvolvido em 1912 na Universidade de Glasgow, no departamento de Obstetrícia, pelo professor lan Donald e seus colegas, os primeiros a utilizarem ultra-som como modalidade diagnóstica.

A idéia de que a radioatividade resulta de uma descarga espontânea de um elemento foi desenvolvida por Frederick Soddy em 1903. Em 1934 Irene Curie e Frederic Joliot produziram isótopos radioativos artificiais e então cientistas de todo o mundo iniciaram pesquisas sobre novos tipos de isótopos. O primeiro uso clínico de "radioatividade artificial" ocorreu em 1937 na Universidade de Berkeley para realização de tratamento de um paciente com leucemia e o grande marco na medicina nuclear foi em 1946 quando um paciente com câncer de tireóide foi tratado com iodo radioativo (http://www.radi-ology.co.uk/radsite/historical.htm). 


\subsection{O Cérebro}

Ainda não está exatamente definida a total capacidade do cérebro humano, mas sabe-se que é a estrutura viva mais complexa que existe no universo. Sabe-se também que o cérebro é o responsável pelo controle de toda atividade corporal, que vai desde funções sexuais até emoções, aprendizado e memória. Além disso, acredita-se que este seja responsável pela resposta do sistema imune e por determinar, em parte, como as pessoas respondem a tratamentos médicos.

O córtex cerebral é divido em quatro partes (lobos): occipital, temporal, parietal e frontal (Figura 4 e 5). Essas regiões são responsáveis por diversas funções, como fala, audição e visão (CAREY, 2005). Algumas vezes são responsáveis por mais de uma função e isto caracteriza o cérebro como um Sistema Inteligente de Processamento Distribuído (SIPD), ou seja, vários grupos de neurônios de diversas áreas do cérebro são recrutados para realizar uma determinada tarefa (FOZ, 2003; ROCHA, MASSAD e PEREIRA JUNIOR, 2005). O cérebro humano tem a capacidade de se adaptar a novas demandas do ambiente e quanto maior sua capacidade de reorganizar circuitos neurais, maior e mais eficiente a adaptação (FOZ et al, 2002; FOZ, 2003). Por exemplo, pacientes com lesões na região pré-frontal do cérebro demonstram um leque de controle e flexibilidade em resposta a questões ambientais (BARCELO e KNIGHT, 2002; MILNER, 1963). 
Por muitas décadas foi considerada uma organização cerebral simétrica, com o hemisfério esquerdo dominando a metade direita do corpo e vice-versa. Entretanto, sabe-se que o hemisfério esquerdo está no comando a maior parte das vezes, independentemente do lado do corpo. Com relação a diferenças morfológicas, alguns exemplos podem ser citados, como a fissura Sylviana (que separa os lobos temporal e parietal), que é maior no lado esquerdo, e também áreas esquerdas da região pré-frontal, como a área da Broca, que são aparentemente menores do que áreas direitas dessa região (IACCINO, 1993). As assimetrias morfológicas estão diretamente relacionadas com as assimetrias funcionais, especialmente quando se trata de funções lingüísticas (WALKER, 1980). O motivo desta diferença é que a maioria das estruturas relatadas como maiores no lado esquerdo, está relacionada com o controle e compreensão da linguagem (IACCINO, 1993).

\subsubsection{A Visão}

Aproximadamente um quarto do cérebro está envolvido no processamento visual. A córnea e o cristalino ajudam a produzir as imagens na retina, que são invertidas, ou seja, objetos da direita para o centro projetam imagens para a parte esquerda da retina e vice-versa e objetos de cima para o centro projetam imagens para a parte inferior e vice-versa. As imagens passam por cada olho através do nervo óptico até o quiasma óptico, aonde algumas 
fibras nervosas se cruzam e assim as duas partes do cérebro recebem imagens dos dois olhos.

Cada olho possui 125 milhões de receptores que transformam a luz em sinais elétricos (CAREY, 2005). Esses receptores são divididos em Cones e Bastonetes (CAREY, 2005; ROCHA, 1999), sendo os primeiros sensíveis a três cores: verde, vermelho e azul, enquanto que os bastonetes podem ser ativados por ondas luminosas de qualquer freqüência (ROCHA, 1999).

Inicialmente, as informações provenientes da retina ativam as áreas visuais primárias, localizadas no lobo occipital, cuja função é extrair características básicas da imagem, como composição de cores, identificação de ângulos, etc. As áreas visuais secundárias, que recebem informações das áreas primárias, analisam características particulares da imagem registrada na retina. O resultado do processamento nas áreas visuais secundárias é transferido para áreas de associação, distribuídas nos lobos temporal e parietal (ROCHA, 1999).

\subsubsection{A Memória}

Diferentes partes do cérebro processam diferentes formas de memória (CAREY, 2005; ROCHA, 1999), mas nenhuma dessas partes é sede do processo (ROCHA, 1999). Informações verbais sobre elementos memorizados 
nas áreas visuais podem ser guardadas no lobo temporal esquerdo, enquanto que informações visuais são guardadas no hemisfério direito. Através do corpo caloso (figura 6) essas informações são associadas e esse processo de memória é chamado memória semântica, onde são guardadas informações biográficas ou descritivas sobre elementos do mundo externo. A memória procedural é a que guarda informações sobre como ações são ou foram realizadas. Esse tipo de memorização ocorre através de neurônios de representação de ato motor, localizados na área da Broca (Figura 5) (uma área do córtex pré-motor), e são ativados tanto em ações realizadas pelo indivíduo ou quando este vê o mesmo ato sendo realizado por outro indivíduo. A memória episódica consiste em guardar relações sobre composição de cenas sensoriais e de suas ocorrências em um determinado período de tempo. Neste tipo de memória, o hipocampo (Figura 6) é muito importante e tem como função organizar episódios através de informações que recebe dos sistemas sensoriais e motores, das áreas de associações parietais e frontais e do sistema límbico, onde as emoções são organizadas. A organização seriada de eventos passados e/ou futuros depende de diversas áreas do cérebro que controlam o tempo e as atividades seriadas. A memória executiva é definida por essa organização e depende também de sistemas enzimáticos. Quando se trata de eventos que ainda irão acontecer, nomeia-se de memória prospectiva e quando os eventos já ocorreram então a memória é denominada retrospectiva. O córtex frontal utiliza muito os mecanismos de memória prospectiva e retrospectiva para elaboração de planos e simulação de suas conseqüências. O 
lobo frontal esquerdo parece estar mais envolvido com a seqüência temporal dos eventos e o direito com a localização espacial das ações realizadas (ROCHA, 1999).

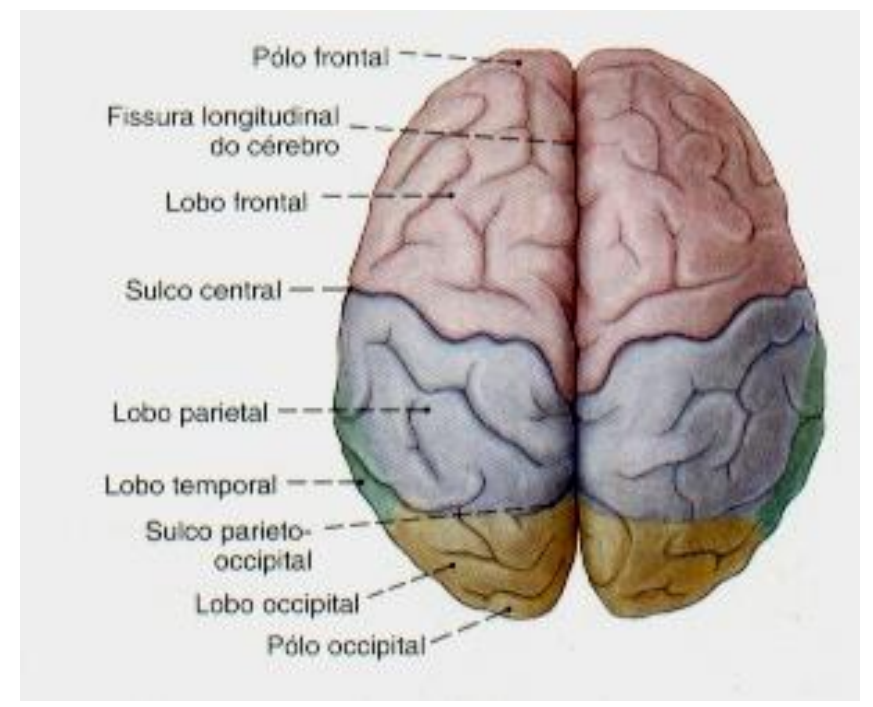

Figura 4 - Lobos cerebrais

(http://www.guia.heu.nom.br/lobos_do_cerebro.htm) 


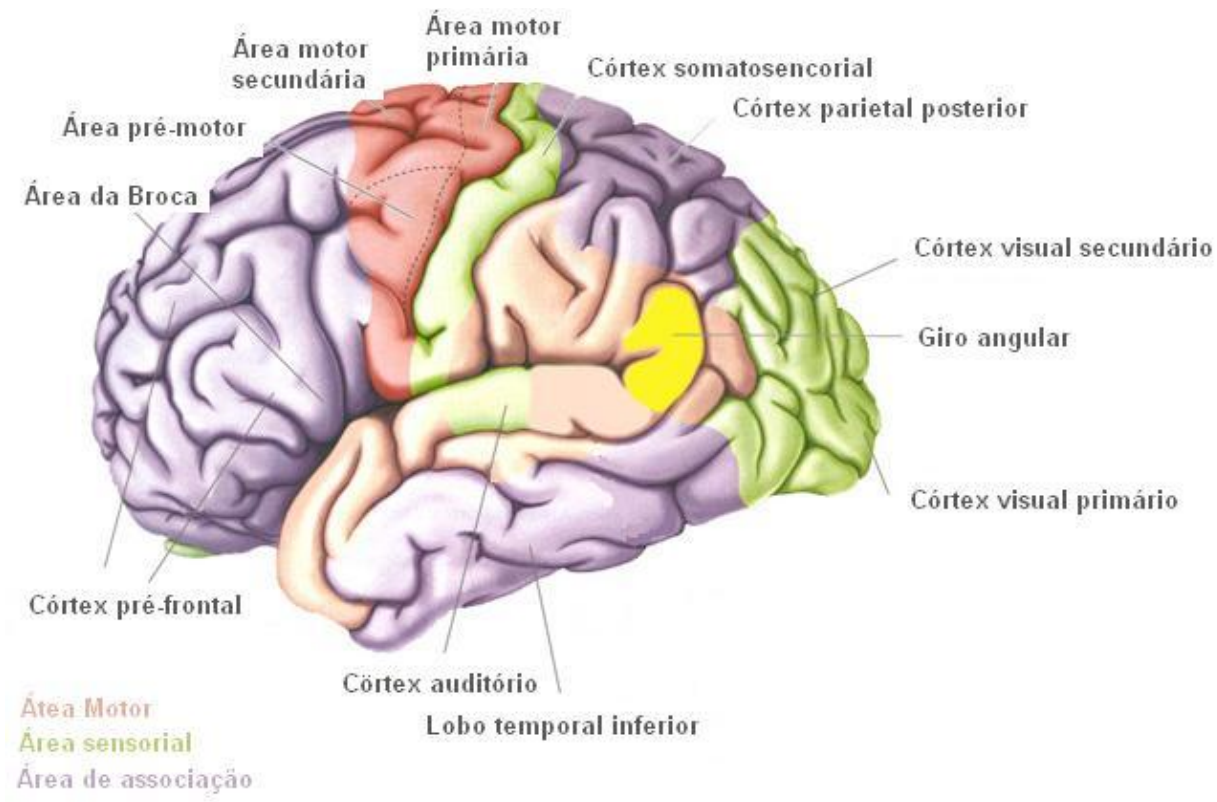

Figura 5 - Área da broca (http://www.sofiatopia.org/equiaeon/henotheism.htm)

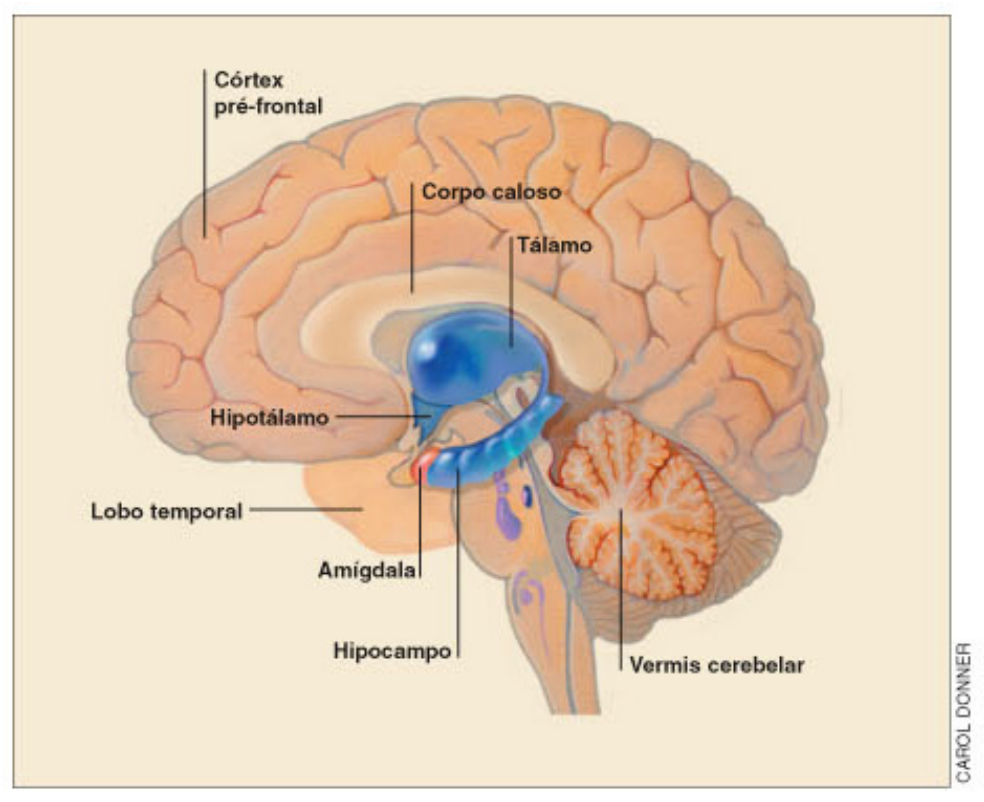

Figura 6 - Hipocampo (http://www.guia.heu.nom.br/hipocampo.htm) 


\subsection{Métodos de Mapeamento Cerebral}

Métodos de mapeamento cerebral e técnicas de neuroimagem têm crescido e avançado rapidamente nos últimos 100 anos. Os métodos têm resultado em desenvolvimento no diagnóstico e monitoramento da terapêutica e têm promovido idéias dos mecanismos básicos de desordens cerebrais (MAZZIOTA, 2000).

Segundo MAZZIOTTA (2000), os métodos de diagnóstico por imagem

podem ser divididos em grupos. Eletroencefalografia e magnetoeletroencefalografia provêm informações de uma constelação de neurônios e uma rede eletromagnética que suas atividades produzem. Estes métodos possuem a melhor resolução temporal, porém apresentam baixa resolução espacial e não demonstram uma localização exata. Tomografia computadorizada (CT), ressonância magnética e imagem vascular usando angiografia convencional, angiografia na ressonância magnética ou CT helicoidal são ideais para avaliação da estrutura cerebral . Um terceiro grupo de métodos provém resposta hemodinâmica como medida da função cerebral e inclui "Xenon-enhanced" CT, ressonância magnética funcional, ressonância magnética de perfusão e fluxo sanguíneo cerebral (PREDA et al, 1998).

A Eletroencefalografia tem conquistado reputação como teste de diagnóstico com uma série de indicações (FOWLE e BINNIE, 2000) e um único 
exame de eletroencefalograma pode ajudar na detecção de epilepsias (BINNIE

e PRIOR, 1994; MAZZIOTA, 2000), pode ser importante na deteç̧ão de recidivas (BERG e SHINNAR, 1991) após uma primeira crise e até mesmo avaliar o risco para o paciente após o término do tratamento com medicamentos. As vantagens e limitações de algumas técnicas de mapeamento cerebral estão resumidas na tabela 1.

Tabela 1. Vantagens e Limitações de Algumas Técnicas de Mapeamento Cerebral

\begin{tabular}{|c|c|c|c|c|}
\hline MÉTODO & $\begin{array}{c}\text { MEDIDAS } \\
\text { FORNECIDAS }\end{array}$ & DOENÇAS & VANTAGENS & LIMITAÇÕES \\
\hline $\begin{array}{l}\text { Tomografia } \\
\text { Computadoriz } \\
\text { ada (CT) }\end{array}$ & $\begin{array}{l}\text { Estrutura cerebral, } \\
\text { integridade da barreira } \\
\text { hemato-encefálica }\end{array}$ & $\begin{array}{l}\text { Hemorragias } \\
\text { agudas ou } \\
\text { crônicas, trauma } \\
\text { agudo, } \\
\text { visualização geral } \\
\text { de estruturas } \\
\text { anatômicas, } \\
\text { atrofia focal ou } \\
\text { generalizada, } \\
\text { hidrocefalia }\end{array}$ & $\begin{array}{l}\text { Excelente imagem } \\
\text { óssea, } 100 \% \text { de } \\
\text { detecção de } \\
\text { hemorragias, baixo } \\
\text { tempo de estudo, pode } \\
\text { escanear pacientes } \\
\text { com equipamento } \\
\text { auxiliar, pode escanear } \\
\text { pacientes com } \\
\text { dispositivo metal ou } \\
\text { eletrônico }\end{array}$ & $\begin{array}{l}\text { Radiação } \\
\text { ionizada, baixa } \\
\text { resolução de } \\
\text { contraste }\end{array}$ \\
\hline $\begin{array}{l}\text { Ressonância } \\
\text { Magnética }\end{array}$ & $\begin{array}{l}\text { Estrutura cerebral, } \\
\text { vascularização cerebral } \\
\text { e cervical, perfusão } \\
\text { cerebral relativa, } \\
\text { concentrações } \\
\text { químicas, estruturas } \\
\text { fibrosas, integridade da } \\
\text { barreira hemato- } \\
\text { encefálica }\end{array}$ & $\begin{array}{l}\text { Isquemia aguda, } \\
\text { neoplasias, } \\
\text { doença } \\
\text { desmielinizante, } \\
\text { foco epilético, } \\
\text { desordens } \\
\text { degenerativas, } \\
\text { infecções, } \\
\text { mapeamento pré- } \\
\text { operatório }\end{array}$ & $\begin{array}{l}\text { Alta resolução } \\
\text { espacial, não emite } \\
\text { radiação ionizante, alto } \\
\text { grau de contraste } \\
\text { branco e preto, sem } \\
\text { artefato ósseo } \\
\text { produzido na fossa } \\
\text { posterior, pode ainda } \\
\text { prover imagem } \\
\text { química, funcional e } \\
\text { angiográfica }\end{array}$ & $\begin{array}{l}\text { Longa duração de } \\
\text { estudo, pacientes } \\
\text { podem ficar } \\
\text { claustrofóbicos, } \\
\text { contra-indicado } \\
\text { em equipamentos } \\
\text { eletrônicos, } \\
\text { hemorragias } \\
\text { agudas } \\
\text { problemáticas, } \\
\text { apenas medidas } \\
\text { relativas }\end{array}$ \\
\hline $\begin{array}{l}\text { Tomografia } \\
\text { emissora de } \\
\text { positron }\end{array}$ & $\begin{array}{l}\text { Perfusão, metabolismo, } \\
\text { extração de susbstrato, } \\
\text { síntese protéica, } \\
\text { integridade } \\
\text { neurotransmissora, } \\
\text { ligação com } \\
\text { receptores, integridade } \\
\text { da barreira hemato- } \\
\text { encefálica }\end{array}$ & $\begin{array}{l}\text { Isquemia, } \\
\text { desordens } \\
\text { degenerativas, } \\
\text { epilepsia, } \\
\text { desordens de } \\
\text { movimento, } \\
\text { desordens } \\
\text { afetivas, } \\
\text { neoplasias, } \\
\text { mapeamento pré- } \\
\text { operatório }\end{array}$ & $\begin{array}{l}\text { Pode desempenhar } \\
\text { imagem } \\
\text { hemodinâmica, } \\
\text { química e funcional, } \\
\text { resultados } \\
\text { quantificáveis, } \\
\text { determinação de } \\
\text { variações fisiológicas, } \\
\text { resolução espacial } \\
\text { uniforme }\end{array}$ & $\begin{array}{l}\text { Radiação } \\
\text { ionizante, alto } \\
\text { custo inicial, longo } \\
\text { tempo de } \\
\text { desenvolvimento } \\
\text { para novos } \\
\text { traçadores, } \\
\text { acesso limitado, } \\
\text { baixo tempo de } \\
\text { resolução }\end{array}$ \\
\hline $\begin{array}{l}\text { Eletroencefa- } \\
\text { lograma }\end{array}$ & Eletrofisiologia & $\begin{array}{l}\text { Epilepsia, } \\
\text { encefalopatias, } \\
\text { desordens } \\
\text { degenerativas, } \\
\text { mapeamento pré- } \\
\text { operatório }\end{array}$ & $\begin{array}{l}\text { Não emite radiação } \\
\text { ionizante, alto tempo } \\
\text { de resolução, pode } \\
\text { identificar focos de } \\
\text { epilepsia }\end{array}$ & $\begin{array}{l}\text { Baixa resolução } \\
\text { espacial, } \\
\text { ponderado por } \\
\text { medidas de } \\
\text { superfície. }\end{array}$ \\
\hline
\end{tabular}




\subsection{O Sistema Computacional}

Em 1997, a EINA - Estudos em Inteligência Natural e Artificial, a APAE Jundiaí e a Faculdade de Medicina da Universidade de São Paulo propuseram o Projeto ENSCER ${ }^{\circledR}$, com o objetivo de desenvolver um sistema para diagnóstico das deficiências e distúrbios de aprendizagem e para auxiliar o desenvolvimento cognitivo das crianças portadoras dessas dificuldades. Esse projeto contou com o apoio financeiro do CNPq - Conselho Nacional de Pesquisas, na sua linha de projetos temáticos em Educação, e a FAPESP Fundação de Amparo à Pesquisa do Estado de São Paulo, tendo sido um dos primeiros projetos financiados através do Programa PIPE - Programa de Inovação em Pequenas Empresas.

Através desse projeto, desenvolveu-se:

1. O software para apoio educacional "Aprendendo com Juca e Laura ${ }^{\circledR}$, cujas atividades informatizadas são desenvolvidas de acordo com o programa curricular de cada série da Educação Infantil e Ensino Fundamental. Esse software é utilizado como ferramenta de apoio, complementando as atividades desenvolvidas em sala de aula e também como ferramenta para a caracterização do desenvolvimento cognitivo da criança, e 
2. o software "Mapeamento Cognitivo Cerebral, MCC", para mapeamento da atividade cerebral associada à solução de atividades informatizadas do software Aprendendo com Juca e Laura ${ }^{\circledR}$ (http://www.enscer.com.br). 


\subsection{Diferenciação entre Gêneros}

Compreender se existe diferenças entre gêneros nas habilidades intelectuais tem sido uma preocupação para os cientistas em diversas disciplinas. HEDGES e NOWELL (1995) realizaram um estudo ao longo de 32 anos e demonstraram que, na maioria das habilidades testadas, a diferença entre homens e mulheres foi pequena. Porém as mulheres apresentaram uma discreta tendência em desenvolver melhor testes de interpretação de texto, enquanto que os homens demonstraram uma tendência em desempenhar melhor tarefas de matemática e estudos sociais. Outro estudo comparativo realizado com 636 estudantes e perguntas sobre conhecimento geral demonstrou que os homens foram significantemente melhores do que as mulheres (LYNN, IRWING e CAMMOCK, 1999).

BAXTER et al. (2003) realizaram um estudo de ressonância magnética com 19 pessoas, sendo 10 do sexo feminino, para comparar possíveis diferenças entre gêneros no processamento de linguagem semântica. Como resultado os homens ativaram áreas esquerdas do cérebro enquanto que as mulheres ativaram áreas cerebrais tanto do lado esquerdo quanto do lado direito.

ROCHA et al (2004 e 2005) demonstraram importante diferença entre gêneros no desempenho de tarefas relacionadas a cálculos aritméticos. Assim, 
os sujeitos do sexo masculino foram mais rápidos que os do sexo feminino nos cálculos aritméticos, embora não tenha havido diferença no porcentual de acertos.

FOZ (2003) realizou um estudo comparativo com 21 voluntários, sendo 11 do sexo feminino e com média de idade de 20 anos e 7 meses. $O$ estudo tinha como objetivo avaliar a atividade cerebral durante processamento de linguagem oral e escrita através de atividades computacionais. Como resultados Foz observou diferenças entre gêneros no tempo de resposta, onde os homens foram mais rápidos nas apresentações orais da atividade e as mulheres mais rápidas nas apresentações textuais das atividades. Com relação à atividade cerebral, as mulheres apresentaram um padrão mais homogêneo de ativação quando comparado aos homens.

IACCINO (1993) relata que alguns estudos demonstram diferenças entre gêneros significantes. Em mulheres a produção da fala ou movimentos das mãos são governados por áreas mais localizadas do que nos homens, particularmente em regiões frontais do hemisfério esquerdo.

Um estudo feito sobre fluxo sangüíneo cerebral demonstrou que durante o teste de analogia verbal, o fluxo sangüíneo no hemisfério esquerdo aumentou significantemente nos dois gêneros, porém quando a tarefa envolvia mais 
componentes espaciais, o grupo feminino demonstrou maior fluxo no lado direito, quando comparado ao grupo masculino (GUR et al, 1982). 


\subsection{Geral}

Avaliar o processo cognitivo diagnóstico em amostra de médicos veterinários especializados em radiologia.

\subsection{Específicos}

1. avaliar o tempo de resposta para o diagnóstico de cada sujeito da amostra;

2. avaliar a porcentagem de acerto de cada sujeito da amostra;

3. avaliar o mapeamento cognitivo cerebral de cada sujeito da amostra;

4. identificar diferenças entre gêneros;

5. identificar diferenças entre os sujeitos da amostra de acordo com seus diferentes tempos de especialidade. 


\section{MATERIAIS E MÉTODOS}




\section{O grupo de Estudo}

Vinte e nove radiologistas veterinários de ambos os sexos (16 mulheres e 13 homens) e com diferentes tempos de especialidade (13 com menos de 1 ano de especialidade, chamados "iniciantes", 8 entre 2 e 5 anos de especialidade, chamados "experientes" e 8 com mais de 5 anos de tempo de especialidade, chamados "seniores") foram convidados a participar do estudo.

Foi garantido o sigilo quanto á identificação dos participantes na amostra.

\section{A Colocação dos Eletrodos}

A colocação dos eletrodos no couro-cabeludo é feita através de um sistema denominado $10-20$, aonde os eletrodos são colocados 10 a $20 \%$ da distância total entre um dado par de pontos referenciais no crânio. Devido a essa variação o exame pode ser realizado tanto em crianças como em adultos macrocefálicos (DUFFY, IYER e SURWILLO, 1999).

Os eletrodos são colocados de modo que todas as partes da cabeça sejam cobertas. Cada área subjacente é denominada com uma letra maiúscula, como F na área frontal, O na occiptal e assim por diante (Figura 7) (DUFFY, IYER e SURWILLO, 1999). 

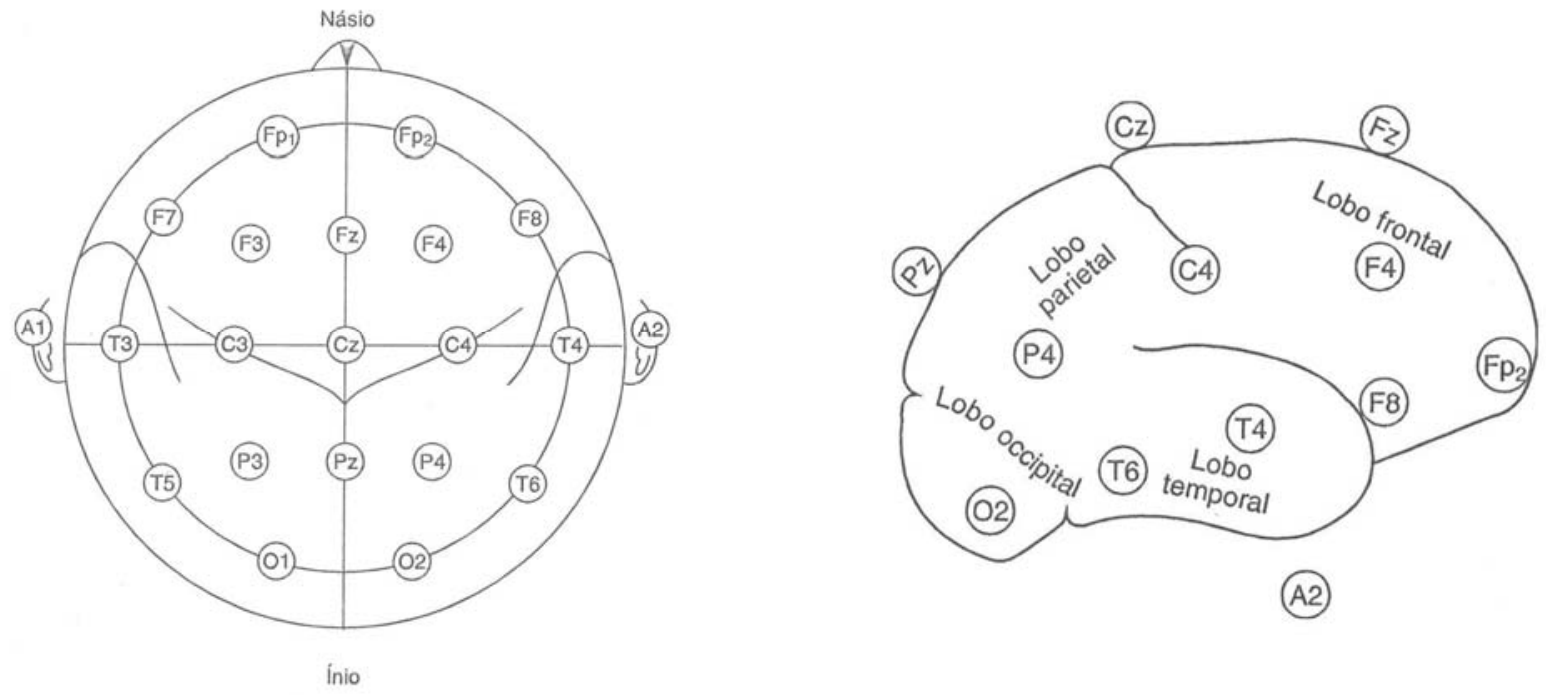

(A2)

Figura 7 - Sistema Internacional 10 - 20 (DUFFY, IYER e SURWILLO, 1999).

Foi colocada uma touca nos voluntários com 20 eletrodos distribuídos no sistema internacional 10-20, que se conectava à um aparelho de EEG. Dois computadores estavam em rede, um deles registrava o eletroencefalograma (EEG) e o outro demonstrava as tarefas para os voluntários e também registrava o desempenho dos mesmos (Figura 8).

\section{As Tarefas}

Quatorze casos foram selecionados, com diferentes níveis de dificuldade a partir de imagens radiográficas de cães e gatos que foram escaneadas e 
colocadas em um programa chamado Enscer (software desenvolvido pela EINA - Estudos em Inteligência Natural e Artificial) adaptado para a realização deste estudo.

Os voluntários foram orientados em como realizar as tarefas e puderam treinar o sistema computacional no primeiro caso, que posteriormente foi descartado. Os casos eram divididos em três partes, nomeadas, história clínica (figura 9), imagem radiográfica (figura 10) e decisão diagnóstica (figura 11).

Após a leitura da história clínica (T1 - tempo de leitura), os voluntários clicavam o botão para mudar de página e o sistema apresentava a imagem radiográfica ( $\mathrm{T} 2$ - tempo da imagem radiográfica) com um ou mais sinais radiográficos. Os voluntários tinham que localizar a posição exata do sinal na imagem. A página seguinte do sistema apresentava quatro opções de diagnóstico (T3 - tempo de diagnóstico) e os voluntários tinham que escolher uma das opções (apenas uma das opções era correta).

Ao longo das três etapas o sistema computacional gravou o tempo que cada voluntário levou para realizar cada etapa e as respostas corretas e incorretas. Além disso, gravou o grau de "incerteza" dos voluntários. Incerteza foi o nome dado a cada vez que o voluntário voltava uma etapa para relê-la. Respostas corretas na etapa da imagem radiográfica foram nomeadas "acerto 
na radiografia" e na etapa do diagnóstico foram nomeadas "acerto no diagnóstico".

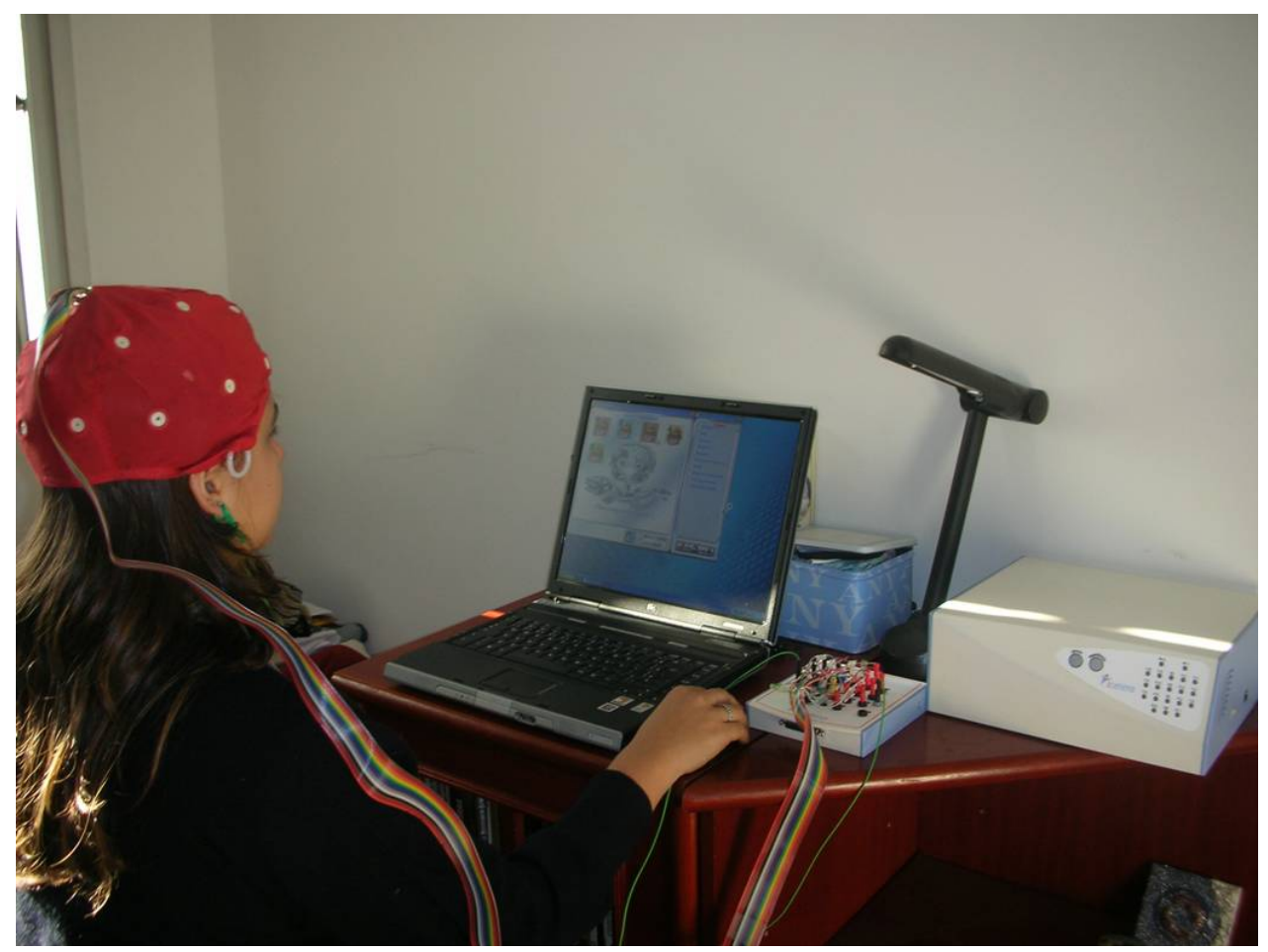

Figura 8 - Voluntário durante a tarefa

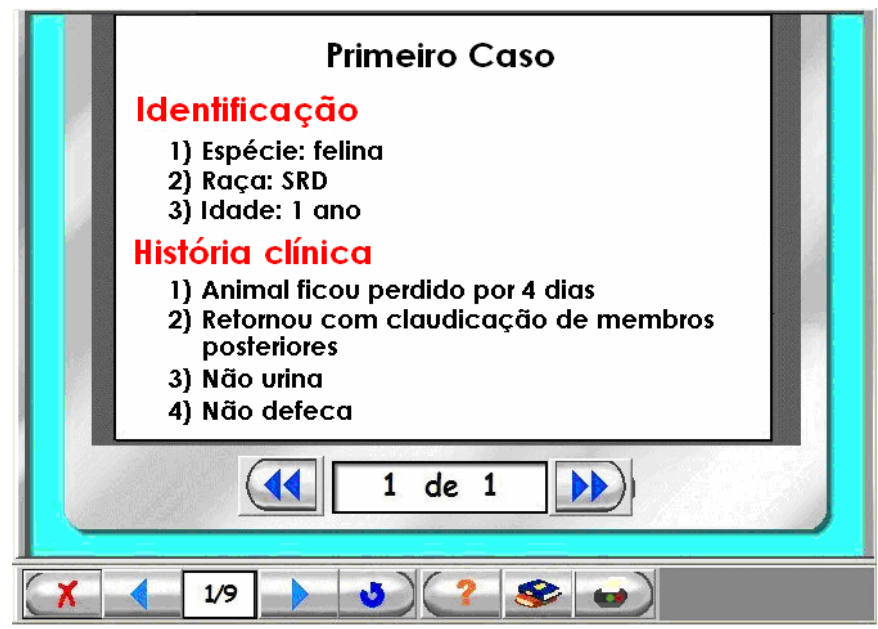

Figura 9 - Primeira etapa (T1) do primeiro caso 


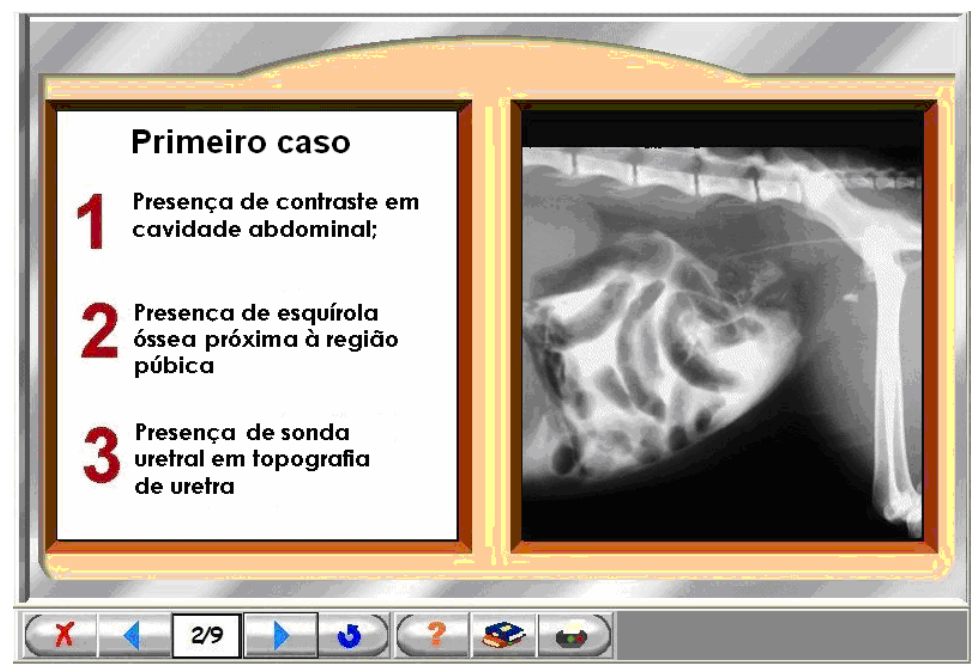

Figura 10 - Segunda etapa (T2) do primeiro caso

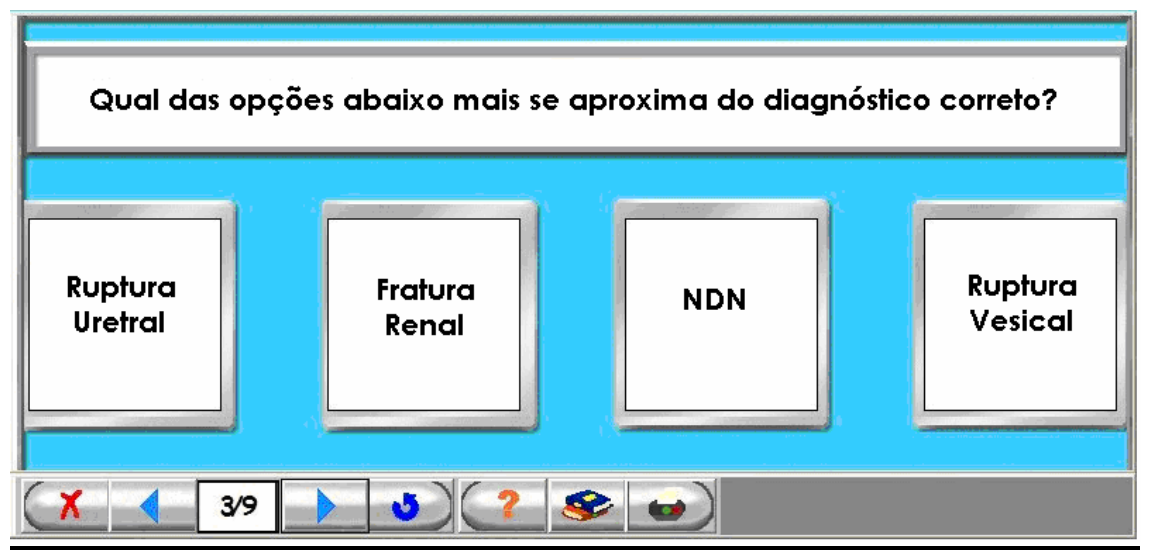

Figura 11 - Terceira etapa (T3) do primeiro

\section{Análise do EEG}

Os coeficientes de correlação linear $r_{i, j}$ entre as atividades de um dos eletrodos $e_{i}$ em relação à atividade dos outros 19 eletrodos $e_{j}$ foram calculados para cada coleta de dados em cada caso clínico e foram utilizados para o cálculo da entropia (Figura 12) (FOZ et al, 2001; ROCHA et al, 2004; ROCHA, MASSAD e PEREIRA JUNIOR, 2005) como: 


$$
\begin{aligned}
& h\left(r_{i, j}\right)=-r_{i, j} \log _{2} r_{i, j}-\left(1-r_{i, j}\right) \log _{2}\left(1-r_{i, j}\right) \\
& . \bar{r}_{i}=\frac{\sum_{1}^{19} \bar{r}_{i, j}}{19^{\cdot}} \\
& . h\left(\bar{r}_{i}\right)=-\bar{r}_{i} \log _{2} \bar{r}_{i}-\left(1-\bar{r}_{i}\right) \log _{2}\left(1-\bar{r}_{i j}\right) \\
& . h\left(c_{i}\right)=\sum_{1}^{19} h\left(\bar{r}_{i}\right)-h\left(r_{i, j}\right)
\end{aligned}
$$

A entropia de correlação $h\left(c_{i}\right)$ é uma medida da incerteza sobre a existência ou não de uma correlação entre as atividades registradas nos pares de eletrodos $e_{i}, e_{j}$. A entropia $h\left(r_{i, j}\right)=1$ para $r_{i, j}=0.5$ e $h\left(r_{i, j}\right)=0$ para $r_{i, j}=0$ ou $r_{i, j}=1$. Desta forma $h\left(r_{i, j}\right)$ mede o quão incerta é a correlação entre a atividade de EEG registrada por $e_{i}, e_{j}$. A entropia $h\left(\bar{r}_{i}\right)$ da media de correlação $\dot{\mathbf{r}}_{\mathbf{i}}$ fornece informações sobre as correlações entre as atividades registradas por $e_{i}$ e todos os outros $e_{j} \mathrm{~s}$. Se $r_{i, j}=0.5$ para todos os $e_{j} \mathrm{~s}$, então $\bar{r}_{i}=0.5 \mathrm{e}$ $h\left(\bar{r}_{i}\right)=1$. Além disso, se $r_{i, j} \rightarrow 0$ para algum $e_{j} \mathrm{~s}, r_{i, j} \rightarrow 1$ para algum outro $e_{j} \mathrm{~s}$ e $r_{i, j} \rightarrow 0.5$ para todos os remanescentes $e_{j}$ s então $\bar{r}_{i}=0.5$ e $h\left(\bar{r}_{i}\right)=1$. Entretanto, se $r_{i, j} \rightarrow 1\left(r_{i, j} \rightarrow 0\right)$ para a maioria dos $e_{j}$ s então $\bar{r}_{i}=1\left(\bar{r}_{i}=0\right) \mathrm{e}$ 
$h\left(\bar{r}_{i}\right)=0$. Todas as outras condições implicam em $h\left(c_{i}\right) \rightarrow 0$. Portanto, o valor de $h\left(c_{i}\right)$ é uma medida de quanto da atividade de EEG registrada em $e_{i}$ pode estar associada à realização de alguma tarefa pelo cérebro.

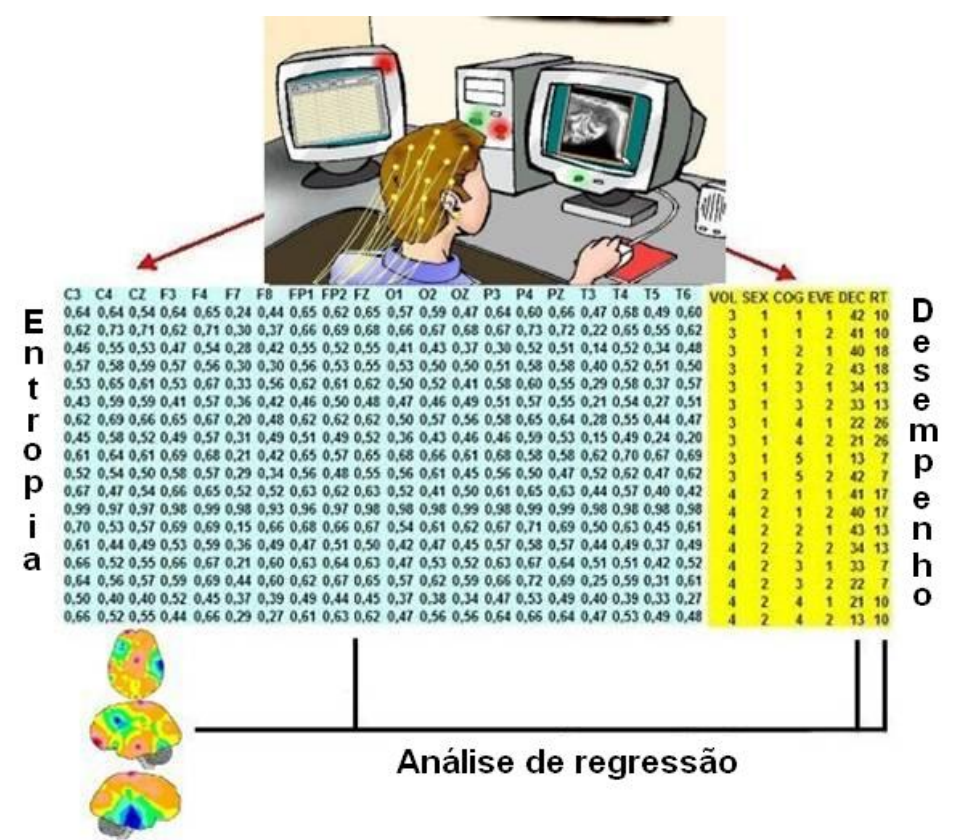

Figura 12 - Cálculo da entropia 
5 RESULTADOS 


\section{Análise de Acordo com o Tempo de Especialidade}

A tabela 2 demonstra o resultado para o tempo, dado em segundos (Posto), em cada etapa (T1 - tempo de leitura; T2 - tempo da imagem radiográfica; T3 - tempo de diagnóstico; Total $=\mathrm{T} 1+\mathrm{T} 2+\mathrm{T} 3$ ) de acordo com o tempo de especialidade dos voluntários ( 1 - iniciantes; 2 - experientes; 3 seniores).

Tabela 2. Etapas $x$ Tempo de especialidade

\begin{tabular}{|cc|c|c|}
\hline & Tempo de Especialidade & N & Posto \\
\hline T1 & 1 & 13 & 16.31 \\
& 2 & 8 & 14.25 \\
& 3 & 8 & 13.63 \\
T2 & Total & 29 & \\
& 1 & 13 & 16.92 \\
& 2 & 8 & 13.25 \\
& 3 & 8 & 13.63 \\
T3 & Total & 29 & \\
& 1 & 13 & 19.46 \\
& 2 & 8 & 11.13 \\
& 3 & 8 & 11.63 \\
& Total & 29 & \\
& 1 & 13 & 18.00 \\
& 2 & 8 & 12.44 \\
& 3 & 8 & 12.69 \\
& & 29 & \\
& & &
\end{tabular}

A tabela 3 demonstra o teste de variabilidade Kruskal Wallis

Tabela 3. Teste estatístico para tempo de especialidade

\begin{tabular}{|l|c|c|c|c|}
\hline & T1 & T2 & T3 & Total \\
\hline Chi-Square & 0.578 & 1.210 & 6.491 & 2.929 \\
df & 2 & 2 & 2 & 2 \\
$\mathrm{p}$ & 0.749 & 0.546 & 0.039 & 0.231 \\
\hline
\end{tabular}


Note que apenas em T3 (tempo de diagnóstico) houve diferença significante entre os três tempos de especialidade.

O gráfico 1 demonstra o boxplot do tempo de especialidade dos voluntários $(1=$ iniciantes, $2=$ experientes e $3=$ seniores $)$ durante a etapa T3 (tempo de diagnóstico).

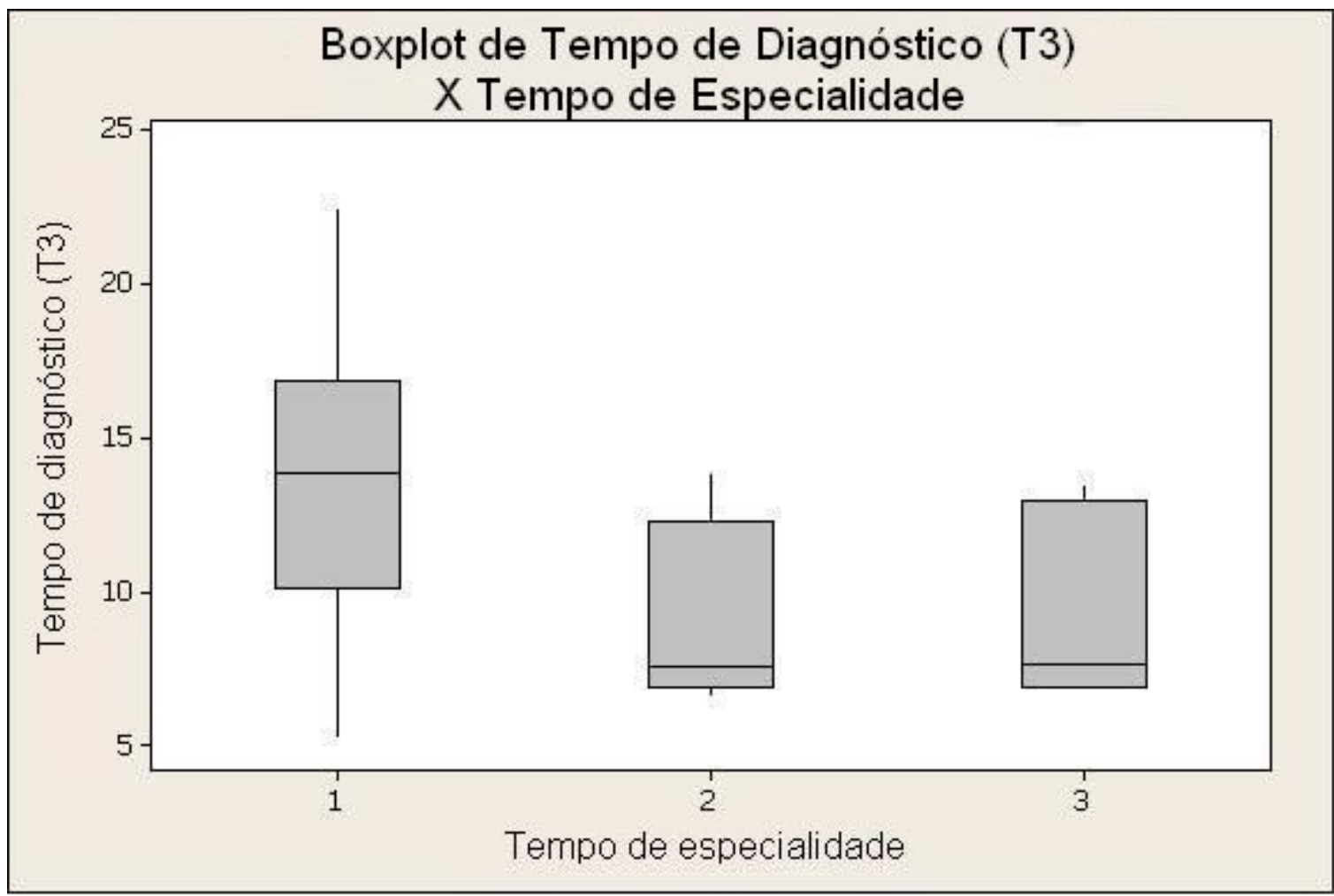

Gráfico 1 - Tempo de Diagnóstico X Tempo de Especialidade

Note que no gráfico o grupo de iniciantes apresentou-se diferente dos grupos experiente e seniores, porém estes dois últimos obtiveram igual tempo realização da etapa T3. 
A tabela 4 demonstra a análise do desempenho de acordo com o tempo de especialidade dos voluntários.

Tabela 4. Desempenho em cada etapa $x$ tempo de especialidade

\begin{tabular}{|l|c|c|c|}
\hline & $\begin{array}{c}\text { Tempo de } \\
\text { especialidade }\end{array}$ & $\mathrm{N}$ & Posto \\
\hline Incertezas & 1 & 13 & 15.23 \\
& 2 & 8 & 18.13 \\
& 3 & 8 & 11.50 \\
Acerto na radiografia & Total & 29 & \\
& 1 & 13 & 7.46 \\
& 2 & 8 & 17.94 \\
Acerto no diagnóstico & 3 & 8 & 24.31 \\
& Total & 29 & \\
& 1 & 13 & 7.77 \\
& 2 & 8 & 16.88 \\
& 3 & 8 & 24.88 \\
& Total & 29 & \\
\hline
\end{tabular}

A tabela 5 demonstra o teste Qui-quadrado para esta variação.

Tabela 5. Teste estatístico para o desempenho diagnóstico

\begin{tabular}{|l|c|c|c|}
\hline & Incertezas & Acerto na radiografia & Acerto no diagnóstico \\
\hline Qui-Quadrado & 2.522 & 21.218 & 20.779 \\
df & 2 & 2 & 2 \\
$\mathrm{p}$ & 0.283 & $<0.0001$ & $<0.0001$ \\
\hline
\end{tabular}

Note que tanto nos acertos na radiografia quanto no diagnóstico houve diferenças estatisticamente significantes entre os três grupos e que nas incertezas não houve diferenças entre os grupos. 
O gráfico 2 demonstra o boxplot do desempenho dos voluntários $(1=$ iniciantes, 2 = experientes e $3=$ seniores) nas radiografias (acerto na radiografia).

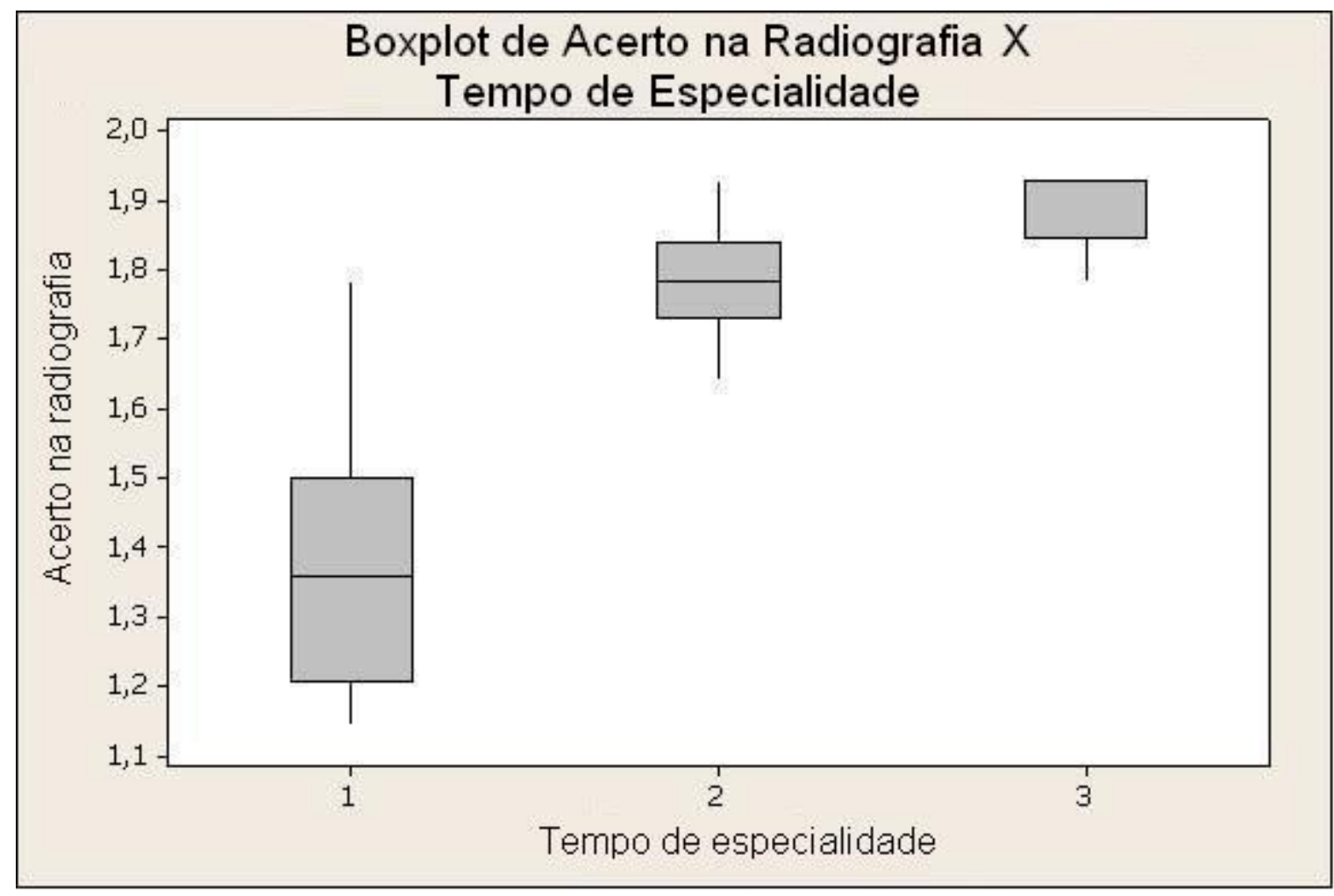

Gráfico 2 - Acerto na Radiografia X Tempo de Especialidade

Note que os três grupos foram distintos no desempenho nas radiografias.

O gráfico 3 demonstra o boxplot do desempenho dos voluntários $(1=$ iniciantes, $2=$ experientes e $3=$ seniores) nas respostas finais (acerto no diagnóstico). 


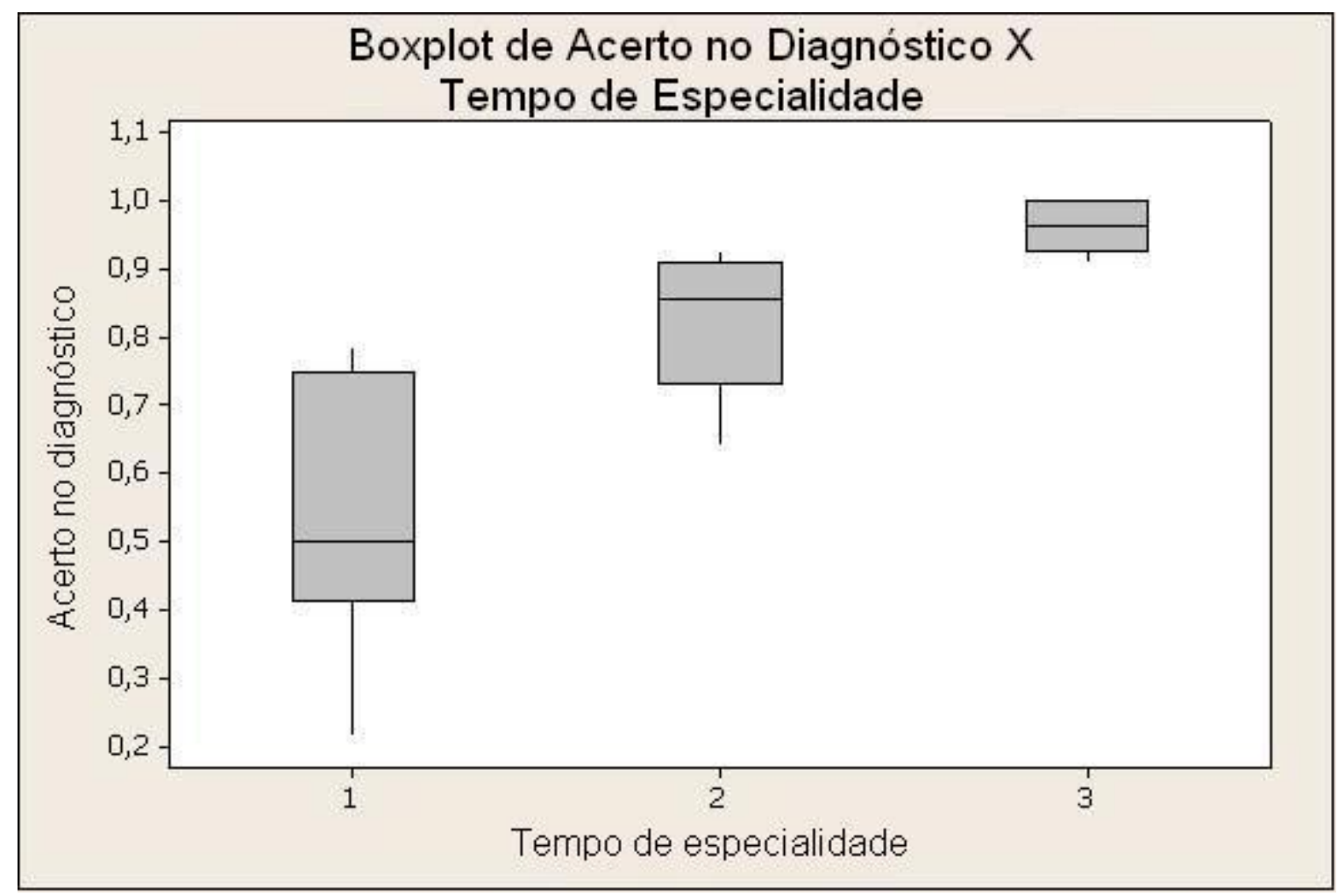

Gráfico 3 - Acerto no Diagnóstico X Tempo de Especialidade

Note que os três grupos foram distintos no desempenho no diagnóstico final.

A tabela 6 demonstra uma comparação apenas entre iniciantes e seniores de acordo com os acertos na radiografia.

Tabela 6. Teste estatístico em acertos na radiografia (iniciantes $x$ seniores)

\begin{tabular}{|l|c|c|c|c|}
\hline Tempo de especialidade & $\mathrm{N}$ & Mediana & Posto & $\mathrm{Z}$ \\
\hline Iniciantes & 13 & 1.357 & 7.0 & -3.73 \\
Seniores & 8 & 1.929 & 17.4 & 3.73 \\
Total & 21 & 11.0 & & \\
$\mathrm{p}$ & & & & $<0.0001$ \\
\hline
\end{tabular}


Note que houve diferença estatística entre os dois grupos analisados.

A tabela 7 demonstra uma comparação apenas entre iniciantes e seniores de acordo com os acertos no diagnóstico.

Tabela 7. Teste estatístico em acertos no diagnóstico (iniciantes $x$ seniores)

\begin{tabular}{|l|c|c|c|c|}
\hline \multicolumn{1}{|c|}{ Tempo de especialidade } & $\mathrm{N}$ & Median & Ave. rank & $\mathrm{Z}$ \\
\hline Iniciantes & 13 & 0.50000 & 7.0 & -3.77 \\
Seniores & 8 & 0.9643 & 17.5 & 3.77 \\
Total & 21 & 11.0 & & \\
$\mathrm{p}$ & & & & $<0.0001$ \\
\hline
\end{tabular}

Note que há uma diferença significante entre os dois grupos analisados.

A tabela 8 demonstra uma comparação entre iniciantes e seniores no tempo de leitura.

Tabela 8. Teste estatístico para tempo de leitura (iniciantes $\mathrm{x}$ seniors)

\begin{tabular}{|l|c|c|c|c|}
\hline Tempo de especialidade & $\mathrm{N}$ & Mediana & Posto & $\mathrm{Z}$ \\
\hline Iniciantes & 13 & 14.93 & 11.8 & 0.80 \\
Seniores & 8 & 12.03 & 9.6 & -0.80 \\
Total & 21 & 11.0 & & \\
$\mathrm{p}$ & & & & 0.426 \\
\hline
\end{tabular}

Note que não houve diferença entre os dois grupos analisados.

A tabela 9 demonstra uma comparação entre iniciantes e seniores no tempo da imagem radiografia 
Tabela 9. Teste estatístico para tempo na imagem radiográfica (iniciantes $x$ seniores)

\begin{tabular}{|l|c|c|c|c|}
\hline Tempo de especialidade & $\mathrm{N}$ & Mediana & Posto & $\mathrm{Z}$ \\
\hline Iniciantes & 13 & 26.79 & 11.9 & 0.87 \\
Seniores & 8 & 22.89 & 9.5 & -0.87 \\
Total & 21 & 11.0 & & \\
$\mathrm{p}$ & & & & 0.385 \\
\hline
\end{tabular}

Note que não houve diferença entre os dois grupos analisados.

A tabela 10 demonstra uma comparação entre iniciantes e seniores no tempo de diagnóstico.

Tabela 10. Teste estatóstico para tempo de diagnóstico (iniciantes $\mathrm{x}$ seniors)

\begin{tabular}{|l|c|c|c|c|}
\hline Tempo de especialidade & $\mathrm{N}$ & Mediana & Posto & Z \\
\hline Iniciantes & 13 & 13.857 & 13.2 & 2.03 \\
Seniores & 8 & 7.617 & 7.5 & -2.03 \\
Total & 21 & 11.0 & & \\
$\mathrm{p}$ & & & & 0.043 \\
\hline
\end{tabular}

Note que houve diferença estatística entre os dois grupos analisados. 


\section{Análise de Acordo com o Gênero}

A tabela 11 demonstra o resultado para o tempo, dado em segundos (Posto), em cada etapa (T1 - tempo de leitura; T2 - tempo da imagem radiográfica; T3 - tempo de diagnóstico; Total $=\mathrm{T} 1+\mathrm{T} 2+\mathrm{T} 3)$ de acordo com o gênero ( 1 - feminino; 2 - masculino; Total $=1+2)$.

Table 11. Etapas x Gênero

\begin{tabular}{|l|c|c|c|c|}
\hline & Sexo & N & Posto & Soma dos Postos \\
\hline T1 & 1 & 16 & 12.75 & 204.00 \\
& 2 & 13 & 17.77 & 231.00 \\
T2 & Total & 29 & & \\
& 1 & 16 & 13.94 & 223.00 \\
& 2 & 13 & 16.31 & 212.00 \\
T3 & Total & 29 & & 229.00 \\
& 1 & 16 & 14.31 & 206.00 \\
& 2 & 13 & 15.85 & 22.00 \\
Total & Total & 29 & & 22.00 \\
& 1 & 16 & 13.25 & \\
& 2 & 13 & 17.15 & \\
\hline
\end{tabular}

A tabela 12 demonstra o teste Mann-Whitney para esta variável.

Tabela 12. Teste estatístico para gêneros

\begin{tabular}{|l|c|c|c|c|}
\hline & T1 & T2 & T3 & Total \\
\hline Mann-Whitney U & 68.000 & 87.000 & 93.000 & 76.000 \\
Z & -1.579 & -0.746 & -0.483 & -1.228 \\
Signif. Asintótica (bicaudal) & 0.114 & 0.456 & 0.629 & 0.219 \\
Signif. Exata (2*bicaudal) & $0.121(\mathrm{a})$ & $0.475(\mathrm{a})$ & $0.650(\mathrm{a})$ & $0.232(\mathrm{a})$ \\
\hline
\end{tabular}


Note que não houve diferença significante entre os dois grupos analisados.

A tabela 13 demonstra análise do desempenho médio de acordo com o gênero $(1-$ feminino; $2-$ masculino; Total $=1+2)$.

Tabela 13. Desempenho em cada etapa de acordo com gênero

\begin{tabular}{|l|c|c|c|c|}
\hline & Sexo & N & Posto & Soma dos Postos \\
\hline Incerteza & 1 & 16 & 12.97 & 207.50 \\
& 2 & 13 & 17.50 & 227.50 \\
& Total & 29 & & \\
Acerto na radiograifa & 1 & 16 & 16.00 & 256.00 \\
& 2 & 13 & 13.77 & 179.00 \\
& Total & 29 & & 258.50 \\
& 1 & 16 & 16.16 & 176.50 \\
& 2 & 13 & 13.58 & \\
& Total & 29 & & \\
\hline
\end{tabular}

A tabela 14 demonstra o teste Mann-Whitney para esta variável.

Tabela 14. Teste estatístico para gêneros

\begin{tabular}{|l|c|c|c|}
\hline & Incerteza & Acerto na radiografia & Acerto no diagnóstico \\
\hline Mann-Whitney U & 71.500 & 88.000 & 85.500 \\
Z & -1.449 & -.710 & -0.816 \\
Signif. Asintótica (bicaudal) & 0.147 & 0.478 & 0.414 \\
Signif. Exata (2*bicaudal) & $0.156(\mathrm{a})$ & $0.503(\mathrm{a})$ & $0.423(\mathrm{a})$ \\
\hline
\end{tabular}

Note que não houve diferença significante entre os grupos analisados. 
A tabela 15 demonstra a análise estatística (Qui-quadrado) entre os grupos masculino e feminino (gênero) e os grupos experientes e seniores (E \& S) no caso 1 (nas etapas T1, T2 e T3 e no desempenho).

Tabela 15. Caso 1 (etapas e desempenho)

\begin{tabular}{|l|c|c|}
\hline & Gênero & E \& S \\
\hline T1 & 0,114 & 0,585 \\
T2 & 0,456 & 0,275 \\
Incerteza & 0,63 & 0,005 \\
Erro na radiografia & 0,299 & 0,299 \\
Erro no diagnóstico & 0,70 & 0,0057 \\
\hline
\end{tabular}

Note que, no primeiro caso, houve diferença estatística entre os voluntários experientes e seniores na terceira etapa e no erro na radiografia.

A tabela 16 demonstra a análise estatística (Qui-quadrado) entre os grupos masculino e feminino (gênero) e os grupos experientes e seniores (E \& S) no caso 2 (nas etapas T1, T2 e T3 e no desempenho).

Tabela 16. Caso 2 (etapas e desempenho)

\begin{tabular}{|l|c|c|}
\hline & Gênero & E \& S \\
\hline T1 & 0,91 & 0,94 \\
T2 & 0,94 & 0,74 \\
T3 & 0,24 & 0,10 \\
Incerteza & 0,448 & 0,44 \\
Erro na radiografia & 0,68 & $<0,0001$ \\
Erro no diagnóstico & 1,0 & 0,0036 \\
\hline
\end{tabular}


Note que, no segundo caso, houve diferença entre experientes e seniores apenas no desempenho (erro na radiografia e erro no diagnóstico).

A tabela 17 demonstra a análise estatística (Qui-quadrado) entre os grupos masculino e feminino (gênero) e os grupos experientes e seniores (E \& S) no caso 3 (nas etapas T1, T2 e T3 e no desempenho).

\section{Tabela 17. Caso 3 (etapas e desempenho)}

\begin{tabular}{|l|c|c|}
\hline & Gênero & E \& S \\
\hline T1 & 0,13 & 0,88 \\
T2 & 0,154 & 0,81 \\
T3 & 0,392 & 0,017 \\
Incerteza & 0,14 & 0,63 \\
Erro na radiografia & 1,00 & 0,078 \\
Erro no diagnóstico & 0,86 & 0,015 \\
\hline
\end{tabular}

Note que, no caso três, os voluntários experientes e seniores foram estatisticamente diferentes na terceira etapa do caso e no erro no diagnóstico.

A tabela 18 demonstra a análise estatística (Qui-quadrado) entre os grupos masculino e feminino (gênero) e os grupos experientes e seniores (E \& S) no caso quatro (nas etapas T1, T2 e T3 e no desempenho). 
Tabela 18. Caso 4 (etapas e desempenho)

\begin{tabular}{|l|c|c|}
\hline & Gênero & E \& S \\
\hline T1 & 0,324 & 0,71 \\
T2 & 0,98 & 0,18 \\
T3 & 0,39 & 0,30 \\
Incerteza & 0,42 & 0,58 \\
Erro na radiografia & 1,0 & 1,0 \\
Erro no diagnóstico & 0,663 & 0,36 \\
\hline
\end{tabular}

Note que não houve diferença entre os voluntários no caso quatro nem nas etapas e nem no desempenho.

A tabela 19 demonstra a análise estatística (Qui-quadrado) entre os grupos masculino e feminino (gênero) e os grupos experientes e seniores (E \& S) no caso cinco (nas etapas T1, T2 e T3 e no desempenho).

Tabela 19. Caso 5 (etapas e desempenho)

\begin{tabular}{|l|c|c|}
\hline & Gênero & E \& S \\
\hline T1 & 0,008 & 0,32 \\
T2 & 0,983 & 0,50 \\
T3 & 0,196 & 0,10 \\
Incerteza & 0,88 & 0,30 \\
Erro na radiografia & 1,0 & 0,01 \\
Erro no diagnóstico & 0,31 & 0,012 \\
\hline
\end{tabular}

Note que, no caso cinco, houve diferença entre os grupos masculino e feminino na primeira etapa (T1) e entre os grupos experientes e seniores no desempenho (erro na radiografia e erro no diagnóstico). 
A tabela 20 demonstra a análise estatística (Qui-quadrado) entre os grupos masculino e feminino (gênero) e os grupos experientes e seniores (E \& S) no caso seis (nas etapas T1, T2 e T3 e no desempenho).

Tabela 20. Caso 6 (etapas e desempenho)

\begin{tabular}{|l|c|c|}
\hline & Gênero & E \& S \\
\hline T1 & 0,58 & 0,01 \\
T2 & 0,36 & 0,15 \\
T3 & 0,214 & 0,34 \\
Incerteza & 0,2275 & 1,0 \\
Erro na radiografia & 1,0 & 0,17 \\
Erro no diagnóstico & 0,464 & 0,42 \\
\hline
\end{tabular}

Note que, no caso seis, houve diferença estatística entre os voluntários experientes e seniores na etapa $\mathrm{T} 1$.

A tabela 21 demonstra a análise estatística (Qui-quadrado) entre os grupos masculino e feminino (gênero) e os grupos experientes e seniores (E \& S) no caso sete (nas etapas T1, T2 e T3 e no desempenho).

Tabela 21. Caso 7 (etapas e desempenho)

\begin{tabular}{|l|c|c|}
\hline & Gênero & E \& S \\
\hline T1 & 0,75 & 0,83 \\
T2 & 0,65 & 0,83 \\
T3 & 0,029 & 0,83 \\
Incerteza & 0,31 & 1,0 \\
Erro na radiografia & 1,0 & 1,0 \\
Erro no diagnóstico & 0,689 & 0,11 \\
\hline
\end{tabular}


Note que não houve diferenças estatísticas entre os voluntários no caso sete.

A tabela 22 demonstra a análise estatística (Qui-quadrado) entre os grupos masculino e feminino (gênero) e os grupos experientes e seniores (E \& S) no caso 8 (nas etapas T1, T2 e T3 e no desempenho).

Tabela 22. Caso 8 (etapas e desempenho)

\begin{tabular}{|l|c|c|}
\hline & Gênero & E \& S \\
\hline T1 & 0,231 & 0,12 \\
T2 & 0,519 & 0,50 \\
T3 & 0,747 & 0,98 \\
Incerteza & 1,0 & 0,17 \\
Erro na radiografia & 1,0 & 0,04 \\
Erro no diagnóstico & 1,0 & 0,057 \\
\hline
\end{tabular}

Note que, no caso oito, houve diferença entre os grupos de experientes e seniores no desempenho (erro na radiografia e erro no diagnóstico).

A tabela 23 demonstra a análise estatística (Qui-quadrado) entre os grupos masculino e feminino (gênero) e os grupos experientes e seniores (E \& S) no caso nove (nas etapas T1, T2 e T3 e no desempenho).

Tabela 23. Caso 9 (etapas e desempenho)

\begin{tabular}{|l|c|c|}
\hline & Gênero & E \& S \\
\hline T1 & 0,040 & 0,51 \\
T2 & 0,751 & 0,68 \\
T3 & 0,51 & 0,54 \\
Incerteza & 0,18 & 0,17 \\
Erro na radiografia & 0,272 & 0,61 \\
Erro no diagnóstico & 1,0 & 1,0 \\
\hline
\end{tabular}


Note que, no caso nove, houve diferença estatística entre homens e mulheres no tempo da etapa T1.

A tabela 24 demonstra a análise estatística (Qui-quadrado) entre os grupos masculino e feminino (gênero) e os grupos experientes e seniores (E \& S) no caso 10 (nas etapas T1, T2 e T3 e no desempenho).

\section{Tabela 24. Caso 10 (etapas e desempenho)}

\begin{tabular}{|l|c|c|}
\hline & Gênero & E \& S \\
\hline T1 & 0,871 & 0,28 \\
T2 & 0,63 & 0,80 \\
T3 & 0,728 & 0,18 \\
Encerteza & 0,39 & 0,69 \\
Erro na radiografia & 1,0 & 0,17 \\
\hline
\end{tabular}

Note que, no caso 10, não houve diferença estatística entre os voluntários.

A tabela 25 demonstra a análise estatística (Qui-quadrado) entre os grupos masculino e feminino (gênero) e os grupos experientes e seniores (E \& S) no caso 11 (nas etapas T1, T2 e T3 e no desempenho). 
Tabela 25. Caso 11 (etapas e desempenho)

\begin{tabular}{|l|c|c|}
\hline & Gênero & E \& S \\
\hline T1 & 0,98 & 0,32 \\
T3 & 0,30 & 0,50 \\
Incerteza & 0,83 & 0,19 \\
Erro na radiografia & 0,59 & 0,59 \\
Erro no diagnóstico & 0,73 & 0,42 \\
\hline
\end{tabular}

Note que, no caso 11, não houve diferença estatística entre os voluntários.

A tabela 26 demonstra a análise estatística (Qui-quadrado) entre os grupos masculino e feminino (gênero) e os grupos experientes e seniores ( $E$ \& S) no caso 12 (nas etapas T1, T2 e T3 e no desempenho).

Tabela 26. Caso 12 (etapas e desempenho)

\begin{tabular}{|l|c|c|}
\hline & Gênero & E \& S \\
\hline T1 & 0,45 & 0,95 \\
T2 & 0,11 & 0,37 \\
T3 & 0,62 & 0,17 \\
Incerteza & 0,98 & 0,85 \\
Erro na radiografia & 1,0 & 0,19 \\
Erro no diagnóstico & 0,86 & 0,096 \\
\hline
\end{tabular}

Note que, no caso 12, não houve diferença estatística entre os voluntários. 
A tabela 27 demonstra a análise estatística (Qui-quadrado) entre os grupos masculino e feminino (gênero) e os grupos experientes e seniores (E \& S) no caso 13 (nas etapas T1, T2 e T3 e no desempenho).

Tabela 27. Caso 13 (etapas e desempenho)

\begin{tabular}{|l|c|c|}
\hline & Gênero & E \& S \\
\hline T1 & 0,94 & 0,39 \\
T2 & 0,77 & 0,44 \\
T3 & 0,94 & 0,42 \\
Incerteza & 0,44 & 0,84 \\
Erro na radiografia & 0,28 & 0,032 \\
Erro no diagnóstico & 0,66 & 0,0001 \\
\hline
\end{tabular}

Note que, no caso 13 , houve diferença estatística entre experientes e seniores no erro no diagnóstico.

A tabela 28 demonstra a análise estatística (Qui-quadrado) entre os grupos masculino e feminino (gênero) e os grupos experientes e seniores (E \& S) no caso 14 (nas etapas T1, T2 e T3 e no desempenho).

Tabela 28. Caso 14 (etapas e desempenho)

\begin{tabular}{|l|c|c|}
\hline & Gênero & E \& S \\
\hline T1 & 0,20 & 0,61 \\
T2 & 0,39 & 0,39 \\
T3 & 0,81 & 0,65 \\
Incerteza & 0,57 & 0,57 \\
Erro na radiografia & 0,91 & 0,20 \\
Erro no diagnóstico & 1,0 & 0,03 \\
\hline
\end{tabular}


Note que, no caso 14, houve diferença estatística entre experientes e seniores no erro no diagnóstico.

A tabela 29 resume os resultados significativos para o estudo.

Tabela 29. Resumo dos resultados

\begin{tabular}{|c|c|}
\hline Variáveis & Valor de $\mathrm{p}$ \\
\hline Tempo de especialidade (1, 2 e 3$) \times$ etapa (T3) & 0,039 \\
\hline Tempo de especialidade $(1,2$ e 3$) \times$ acerto na radiografia & $<0,0001$ \\
\hline Tempo de especialidade $(1,2$ e 3$) x$ acerto no diagnóstico & $<0,0001$ \\
\hline Acerto na radiografia (iniciantes $\mathrm{x}$ seniores) & $<0,0001$ \\
\hline Acerto no diagnóstico (iniciantes $\mathrm{x}$ seniores) & $<0,0001$ \\
\hline Tempo de diagnóstico (iniciantes $\mathrm{x}$ seniores) & 0,043 \\
\hline Caso 5 (etapa T1) (feminino x masculino) & 0,008 \\
\hline Caso 9 (etapa T1) (feminino x masculino) & 0,04 \\
\hline Caso 1 (etapa T3) (experientes $x$ seniores) & 0,01 \\
\hline Caso 3 (etapa T3) (experientes $x$ seniores) & 0,005 \\
\hline Caso 6 (etapa T1) (experientes $x$ seniores) & 0,017 \\
\hline Caso 1 (erro na radiografia) (experientes $x$ seniores) & 0,0057 \\
\hline Caso 2 (erro na radiografia) (experientes $\mathrm{x}$ seniores) & $<0,0001$ \\
\hline Caso 5 (erro na radiografia) (experientes $x$ seniores) & 0,01 \\
\hline Caso 8 (erro na radiografia) (experientes $x$ seniores) & 0,04 \\
\hline Caso 2 (erro no diagnóstico) (experientes $x$ seniores) & 0,0036 \\
\hline Caso 3 (erro no diagnóstico) (experientes $x$ seniores) & 0,015 \\
\hline Caso 5 (erro no diagnóstico) (experientes $x$ seniores) & 0,012 \\
\hline Caso 8 (erro no diagnóstico) (experientes $\mathrm{x}$ seniores) & 0,057 \\
\hline Caso 13 (erro no diagnóstico) (experientes $x$ seniores) & 0,0001 \\
\hline Caso 14 (erro no diagnóstico) (experientes $x$ seniores) & 0,03 \\
\hline
\end{tabular}




\section{Análise dos Mapeamentos Cerebrais}

A figura 13 demonstra o mapeamento cerebral para a regressão entre o processamento do tempo total $(\mathrm{T} 1+\mathrm{T} 2+\mathrm{T} 3)$ para ambos os sexos e para mulheres e homens separadamente.

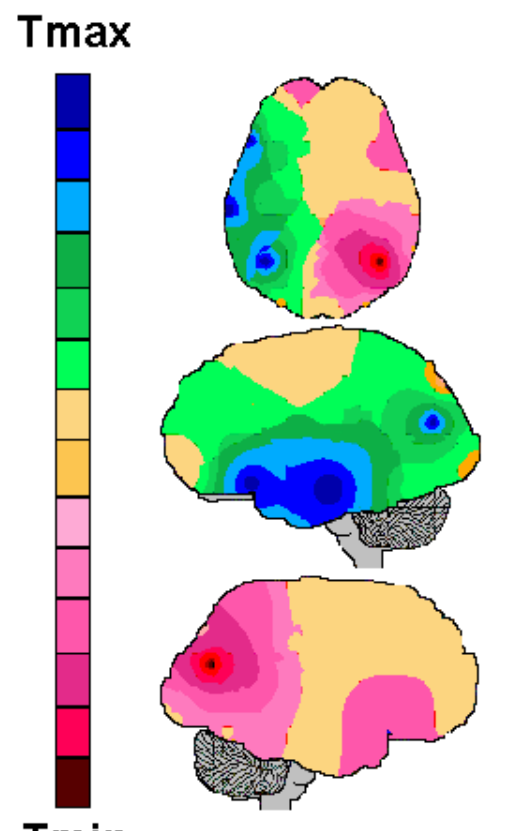

Tmin

A

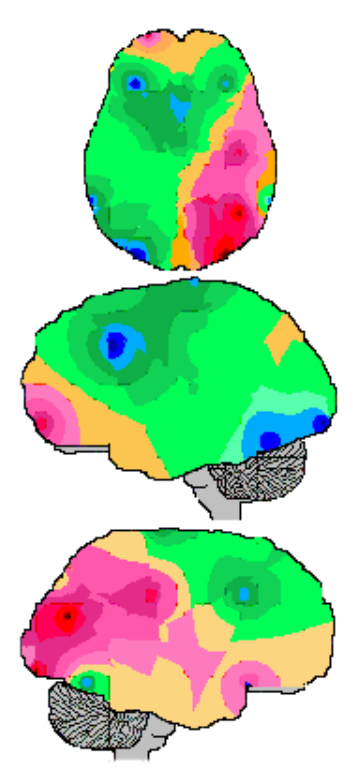

$\mathbf{F}$

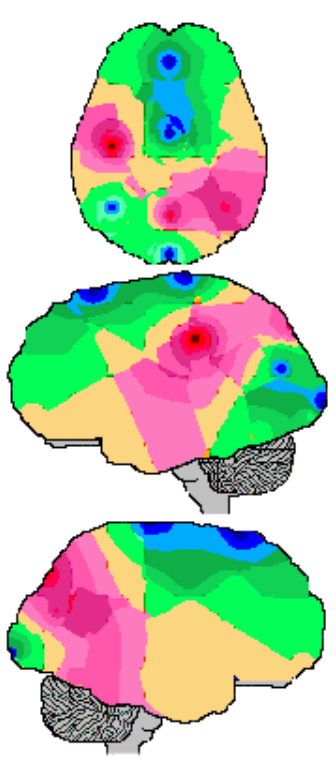

M

Figura 13 - Regressão entre o processamento do tempo total e gênero (agrupados (A) e separados: feminino (F) e masculino (M)). Áreas em azul representam maior tempo de processamento cerebral

Note que existe uma clara diferença entre gêneros. O grupo feminino maximizou o tempo de processamento predominantemente nas áreas do lobo frontal esquerdo (F3) e occipital (O1) e o grupo masculino maximizou o tempo 
de processamento cerebral nas áreas do lobo central frontal $(F Z)$ e áreas centrais $(\mathrm{CZ})$.

A figura 14 demonstra o mapeamento cerebral para a regressão do tempo de especialidade, levando em consideração o tempo de especialidade de cada voluntário, diferente da divisão feita por grupos anteriormente.

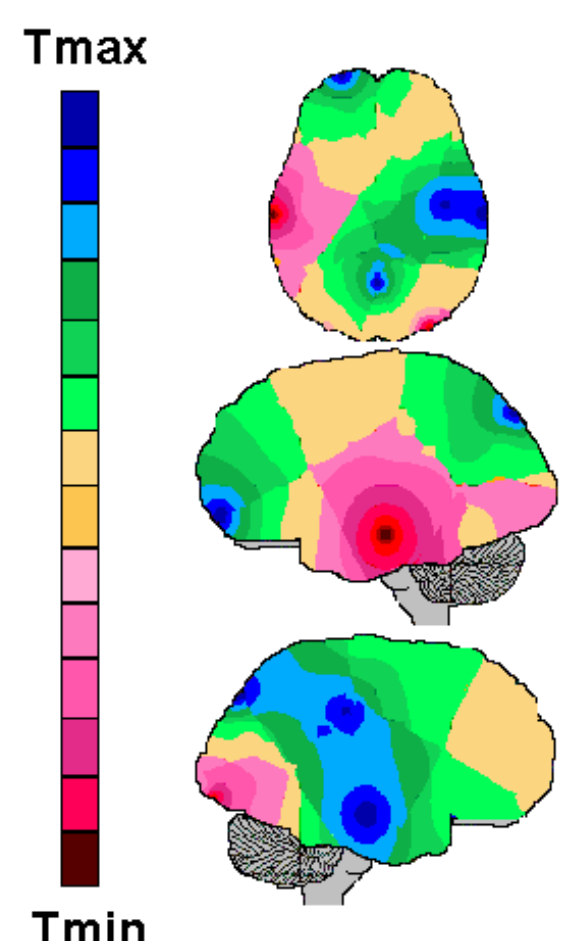

Figura 14 - Análise de regressão no tempo de especialidade. Áreas em azul representam voluntários com maior tempo de especialidade e em vermelho representam os com menor tempo de especialidade

Note que os voluntários com maior tempo de especialidade processaram áreas do lobo parietal direito (P4), lobo temporal direito (T4) e frontal esquerdo 
(FP1), enquanto que os menos experientes processaram áreas no lobo temporal esquerdo (T3) 


\section{DISCUSSÃO}


É muito difícil fazer um contraponto da literatura em relação ao objeto desta dissertação. Uma busca sob as palavras chaves ["cognition" and "veterinary diagnosis"] nas bases PubMed (http://www.ncbi.nlm.nih.gov/sites/entrez?db=pubmed), $\quad$ no $\quad$ ISI (http://apps.isiknowledge.com/UA_GeneralSearch_input.do?product=UA\&searc h_mode=GeneralSearch\&SID=N26HE9@mE8F9aopEIIH\&preferencesSaved), no Science Direct (http://www.sciencedirect.com/) e no Scopus (http://www.scopus.com/scopus/home.url) não revelou nenhum artigo. Em contrapartida, em medicina humana alguns artigos sobre diagnóstico e cognição se destacam.

Várias têm sido as tentativas de se identificar as possíveis vias cognitivas relacionadas ao diagnóstico em medicina humana (MASSAD et al, 2008). Assim, SACKETT et al (1997) propuseram quatro diferentes estratégias para o diagnóstico clínico. A primeira estratégia é chamada de reconhecimento de padrões, e se baseia em métodos de gestalt. É definida como a "percepção instantânea de que a apresentação do paciente está em conformidade com padrões de doença previamente aprendidos" (SACKETT et al, 1997). Normalmente esta estratégia é sensorial e reflexiva. Os médicos a adotam, mas 
não conseguem explicá-la a terceiros, nem o porquê nem o como o fazem. Esta estratégia é aplicada por clínicos experientes e é freqüentemente descrita como intuitiva. Normalmente, o diagnóstico é realizado à primeira vista do paciente. Um exemplo desta abordagem é o diagnóstico de parkinsonismo, no qual o médico rotula o paciente muito rapidamente pela observação de sua marcha ou pelo modo como o paciente articula as palavras.

A segunda estratégia é chamada de arborização do diagnóstico. É definida como "a progressão do processo diagnóstico através de um grande número de vias potenciais por um método no qual a resposta a cada questão diagnóstica leva automaticamente à questão seguinte e no final ao diagnóstico correto (SACKETT et al, 1997). É um método lógico e baseia-se em algoritmos e diagramas de fluxo e é particularmente útil quando o inquérito é populacional ao invés de terapêutico. Este método é muito usado quando o diagnóstico é delegado dos médicos às enfermeiras ou para-médicos.

A terceira estratégia é chamada de estratégia de exaustão. É definida como "a busca incessante e invariante de todos os fatos médicos do paciente, seguido de uma peneiração dos fatos relevantes ao diagnóstico" (SACKETT et al, 1997). Este método é muito demorado e é realizado em duas etapas: a primeira consiste na coleta de todos os dados potencialmente relevantes e a segunda na busca entre os dados do diagnóstico em si. A estratégia de exaustão é o método dos iniciantes e é abandonada com a experiência. 
A quarta estratégia é chamada de estratégia hipotético-dedutiva e é usada por virtualmente todos os médicos, virtualmente o tempo todo. É a "formulação a partir das primeiras pistas sobre o paciente de uma lista curta ações ou de diagnósticos potenciais, seguida das manobras clínicas e complementares que irão reduzir o tamanho da lista a um mínimo coerente" (SACKETT et al, 1997). A abordagem hipotético-dedutiva é considerada o processo diagnóstico mais apropriado por economizar tempo e por ter a maior acurácia.

ALLEN, AROCHA e PATEL (1998) demonstraram que o raciocínio clínico é diferente na dependência do nível de especialização, coleta e uso e interpretação de evidências clínicas. Além disso, demonstraram, como AROCHA e PATEL (1995) e PATEL e GROEN (1986), PATEL, et al (1989), PATEL, GROEN e AROCHA (1990) e PATEL, AROCHA e KAUFMAN (1994), diferenças importantes no desempenho diagnóstico de médicos com tempo de especialidade diferentes. Assim, a porcentagem de acertos diagnósticos cai dos níveis de novatos para médicos residentes e sobe para médicos seniores, numa curva em "J". A quantidade de exames subsidiários, por sua vez, tem padrão inverso.

O único artigo relacionando os processos cognitivos com o diagnóstico veterinário que encontramos foi o artigo de HARDIN (2002), que estudou o desempenho de alunos do segundo ano de veterinária na solução de problemas 
clínicos. Estes autores também identificaram várias estratégias diferentes para a solução dos problemas clínicos apresentados. Os autores concluem que os estudantes apresentam características compatíveis com os padrões de solução de novatos, como já se esperava.

Alguns trabalhos foram realizados com objetivo de avaliar o desempenho de radiologistas (KUNDEL, 2006; POTCHEN, 2006; GROOPMAN, 2007) e a diferenciação entre gêneros (HEDGES e NOWELL, 1995, LYNN, IRWING e CAMMOCK, 1999; BAXTER et al, 2003). Os resultados obtidos neste estudo indicaram que os voluntários com maior tempo de experiência foram mais rápidos do que os voluntários iniciantes no que diz respeito ao tempo de leitura T3, ou seja, a última etapa da tarefa, e também apresentaram melhor desempenho nos acertos nas radiografias e nos diagnósticos. Quando se avaliou os casos separadamente, algumas diferenças entre gêneros foram observadas, mas quando agrupados, os grupos masculino e feminino apresentaram desempenho e tempo de resposta estatisticamente iguais.

Os métodos de mapeamento cerebral e a tecnologia computacional têm evoluído rapidamente nas últimas décadas (MAZZIOTA, 2000; BUTCHER, PERRY e HAHN, 2004) e um dos objetivos deste estudo foi unir a tecnologia da avaliação computacional com a eletroencelafografia. Através projeto ENSCER ${ }^{\circledR}$ isto pode ser realizado e os resultados obtidos do mapeamento cerebral demonstraram que, mesmo os grupos masculino e feminino terem sido 
estatisticamente iguais no quesito tempo de resposta e desempenho, o mapeamento cerebral foi diferente. Isso demonstra que apesar da diferença no processamento cerebral das tarefas, o desempenho dos grupos foi igual. $\mathrm{O}$ grupo feminino maximizou o tempo de processamento predominantemente nas áreas do lobo frontal esquerdo (F3) e occipital (O1). O grupo masculino maximizou o tempo de processamento cerebral nas áreas do lobo central frontal (FZ) e áreas centrais (CZ). Como visto anteriormente o lobo occipital tem como função extrair características básicas da imagem, como composição de cores e identificação de ângulos e o lobo frontal esquerdo parece estar envolvido com seqüência temporal de eventos (ROCHA, 1999). Esta diferença no mapeamento cerebral sugere que homens e mulheres utilizam diferentes estratégias para realização de uma mesma tarefa e que mesmo com as diferenças estratégicas, o desempenho final é o mesmo. Os únicos casos em que houve diferença estatística no tempo de leitura entre gêneros foram os casos cinco e nove, onde o valor de "p" foi inferior à 0,05 em T1 (Tabela 29), porém estes casos não apresentavam nenhuma característica em especial que justificasse essa diferença.

Alguns estudos citados (GUR et al, 1982; IACCINO, 1993; HEDGES e NOWELL, 1995; BAXTER et al, 2003; FOZ, 2003) demonstraram resultados diferentes do presente estudo na comparação entre gêneros, porém estes trabalhos foram realizados com atividades de linguagem, enquanto que este estudo foi realizado com imagens radiográficas. 
O mapeamento realizado agrupando os radiologistas veterinários demonstrou que voluntários com maior tempo de especialidade processaram áreas do lobo parietal direito (P4), temporal direito (T4) e frontal esquerdo (FP1), enquanto que os menos experientes processaram áreas no lobo temporal esquerdo (T3). O lobo temporal esquerdo tem como função guardar informações verbais sobre elementos memorizados, enquanto que informações visuais são guardadas no hemisfério direito. Isso demonstra que radiologistas com maior tempo de especialidade se utilizaram, de uma maneira geral, da memória visual, enquanto que iniciantes utilizaram mais a memória verbal.

Este é o primeiro estudo de desempenho cognitivo de veterinários radiologistas através de um sistema computacional e, portanto, é de fundamental importância a citação de algumas limitações do estudo. Para detectar maiores diferenças no desempenho dos voluntários, seria necessária uma amostra maior. Outra observação importante a ser feita é que o critério utilizado para ordenar os grupos de especialistas em iniciantes, experientes e seniores, foi arbitrário. A especialidade radiológica na medicina veterinária é diferente da medicina humana, onde todos os radiologistas realizaram residência para obtenção de tal título. Neste estudo foi levado em consideração o tempo que os voluntários tinham de convívio com a disciplina, seja através de residência, seja através de cursos extracurriculares. 


\section{CONCLUSÕES}


Neste estudo foi avaliado o mapeamento cognitivo cerebral, o tempo de resposta e o desempenho nas tarefas de médicos veterinários especializados em radiologia. Com estas avaliações foi possível concluir que: radiologistas veterinários com maior tempo de especialidade foram estatisticamente mais rápidos nas tarefas e tiveram melhor desempenho diagnóstico;

(2) voluntários com maior tempo de especialidade ativaram áreas cerebrais diferentes dos menos experientes;

(3) o desempenho diagnóstico foi quantitativamente igual em voluntários de ambos os gêneros;

(4) o mapeamento cerebral do grupo masculino foi diferente do grupo feminino, mesmo com desempenho igual nas tarefas, sugerindo que os grupos se utilizaram de estratégias diferentes para uma mesma tarefa; 
ALLEN, V. G., AROCHA, J. F. e PATEL, V. L. Evaluating evidence against diagnostic hypotheses in clinical making by students, residents and physicians. International Journal of Medical Informatics, v. 51, p. 91-105, 1998.

AROCHA, J. F. e PATEL, V. L. Novice diagnostic reasoning in medicine: accounting for clinical evidence. Journal of Learning Sciences, v. 4(4), p. 35584, 1995.

BARCELO, F.; KNIGHT, R. T. Both random and perseverative errors underlie WCST deficits in prefrontal patients. Neuropsychologia, v. 40, p. 349-56, 2002.

BAXTER, L. C.; SAYKIN, A. J.; FLASHMAN, L. A.; JOHNSON, S.C.; GUERIN, S. J.; BABCOCK, D.C.; WISHART, H.A. Sex differences in semantic language processing: a functional MRI study. Brain Lang., v. 84, p. 264-72, 2003.

BERG, A. T.; SHINNAR, S. The risk of recurrence following a first unprovoked seizure. Neurology, v. 41, p. 965-72, 1991.

BINNIE, C. D.; PRIOR, P. F. Electroencefalography. J. Neurosurg. Psychiatry, v. 57, p. 1308-19, 1994.

BUTCHER, J. N.; PERRY, J.; HAHN, J. Computers in clinical assessment: historical developments, present status, and future challenges. J. Clin. Psychology, v. 60(3), p. 331-45, 2004.

CAREY, J. Brain facts: a primer on the brain and nervous system. Washington (DC): Society for Neuroscience; 2005 
Clinical neurophysiology review [on line]. Disponível em: http://www.neurophysiologyreview.com/eeg.html. Acesso em: 20/07/2007.

DUFFY, F. H.; IYER, V. G.; SURWILLO, W. W. Eletroencefalografia clínica e mapeamento cerebral topográfico: tecnologia e prática. Tradução de Vilma Ribeiro de Souza Varga. Rio de Janeiro: Revinter; 1999.

Enscer: ensinando o cérebro [on line]. Disponível em: http://www.enscer.com.br. Acesso em: 08/08/2007.

FREEDMAN, M; OSICKA, T. Reader variability: what we can learn from computer-aided detection experiments. J. Am. Coll. Radiol., v. 3, p. 446-55, 2006.

FOWLE, A. J.; BINNIE, C. D. Uses and abuses of the EEG in epilepsy. Epilepsia, v. 41, p. 10-18, 2004.

FOZ, F. F. S. B.; LUCHINI, F. L. P.; PALMERI, S.; ROCHA, A. F.; RODELA, E. C.; RONDÓ, A. G.; CARDOSO, M. B.; RAMAZZINI, P. B.; LeITE, C. C. Language Plasticity Revealed by EEG Mapping. Pedriat. Neurol., v. 26, p. 10615, 2002.

FOZ, F. F. S. B. Análise da atividade cerebral durante o processamento de linguagem oral e escrita: estudo comparativo entre gêneros. São Paulo: Faculdade de Medicina, Universidade de São Paulo; 2003.

GROOPMAN, J. How doctors think. Boston: Houghton Mifflin Company; 2007. p. $177-287$. 
GUR, R. C.; GUR, R, E.; OBRIST, W. D.; HUNGERBUHLER, J. P.; YOUNKIN, D.; ROSEN, A. D.; SCKOLNICK, B. E.; REIVICH, M. Sex and handedness differences in cerebral blood flow during rest and cognitive activity. Science, v. 217, p. 659-61, 1982.

HARDIN, L. E. Cognitive processes of second-year veterinary students in clinical case resolution. Journal of Veterinary Medicine Education, v. 30(3), p. 227-36, 2002.

HEDGES, L. V.; NOWELL, A. Sex differences in mental test-scores, variability, and numbers of high-scoring individuals. Science, v. 269, p. 41-5, 1995.

Hipocampo [on line]. http://www.guia.heu.nom.br/hipocampo.htm. Acesso em: 09/08/07.

IACCINO, J. F. Left brain-right brain differences: inquires, evidence, and new approaches. Hillsdale: Lawrence Erlbaum Associates; 1993.

KOECHLIN, E.; HYAFIL, A. Anterior prefrontal function and the limits of human decision-making. Science, v. 318, p. 594-98, 2007.

KORDIN, K. Decision theory: What "Should" the nervous system do? Science, v. 318, p. $606-10,2007$.

KUNDEL, H. L. Images: image quality and observer performance. Radiology, v. 132, p. 265-71, 1979.

KUNDEL, H. L. History of research in medical image perception. J. Am. Coll. Radiol., v. 3, p. 402-8, 2006. 
LYNN, R.; IRWING, P.; CAMMOCK, T. Sex differences in general knowledge. Intelligence, v. 30, p. 27-39, 2001.

Luigi galvani. $\quad$ Disponível em: http://br.geocities.com/saladefisica9/biografias/galvani.htm. Acesso em: 01/02/08.

MASSAD, E., ORTEGA, N. R. S., BARROS, L. C. e STRUHCINED, C. J. Fuzzy Logic in Action: Applications in Epidemiology and Beyond. Heildelberg: Springer Verlag; 2008

MAZZIOTA, J. C. Imaging: window on the brain. Arch. Neurol., v. 57, p. 1413$21,2000$.

MILNER, B. The effects of different brain lesions on card sorting. Arch. Neur., v. 9, p. 90-100, 1963.

NGATEGIZE, P. K.; KANEENE, J. B.; HARSH, S. B.; BARTLETT, P. C.; MATHER, E. L. Decision analysis in animal health programs: merits and limitations. Preventive Veterinary Medicine, v. 4, p. 187-97, 1986.

On Henotheism [on line]. Disponível em: http://www.sofiatopia.org/equiaeon/henotheism.htmggg. Acesso em: 01/02/08.

PATEL, V. L. e GROEN, G. J. Knowledge-based solution strategies in medical reasoning. Cognitive Science, v. 10, p. 91-116, 1986. 
PATEL, V. L., EVANS, D. A. e KAUFMAN, D. R. Cognitive framework for doctor-patient interaction, in: DA Evans and VL Patel. Cambridge: MIT Press; 1989. p. 253-308.

PATEL, V. L., GROEN, J. F. e AROCHA, J. F. Medical expertise as a function of task difficulty. Memory and Cognition, v. 18(4), p. 394-406, 1990.

PATEL, V. L., AROCHA, J. F. e KAUFMAN, D. R. Diagnostic reasoning and expertise, in: D Medin (ed), The Psychology of Learning and Motivation: Advances in Research and Theory; 1994, v. 31, p. 137-252.

PAULUS, M. P. Decision-making dysfunctions in psychiatry - altered homeostatic processing? Science, v. 318, p. 602-6, 2007.

POTCHEN, E. J. Measuring observer performance in chest radiology: some experiences. J. Am. Coll. Radiol., v. 3, p. 423-32, 2006.

PREDA, L.; GAETANI, P.; RODRIGUES Y BAENA, R. et al. Spiral CT angiography and surgical correlation of intracranial aneurysms. Eur. Radiol., v. 8, p. 739-45, 1998.

Radiology: a brief history [on line]. Disponível em: http://www.rad-iology.co.uk/radsite/historical.htm. Acesso em: 13/01/08.

ROCHA, A. F. O Cérebro: um breve relato de sua função. Jundiaí: EINA; 1999. 
ROCHA, F. T.; ROCHA, A. F., MASSAD, E.; MENEZES, R. 2004. Brain mappings of the arithmetic processing in children and adults. Cognitive Brain Research, v. 22, p. 359-72, 2004.

ROCHA, A. F.; MASSAD, E.; PEREIRA JUNIOR, A. The brain: from fuzzy arithmetic to quantum computing. Berlin: Springer-Verlag Berlin Heidelberg; 2005.

THE RANDOM HOUSE COLLEGE DICTIONARY. Nova York: Random House; 1998.

SACKETT, D. L., RICHARDSON, W. S., ROSEMBERG, W. e HAYNES, R. B. Evidence-based medicine: How to practice and reach EBM. New York: Churchill Livingstone; 1997.

SMITH, R. D.; SLENNING, B. D. Decision analysis: dealing with uncertainty in diagnostic testing. Preventive Veterinary Medicine, v. 45, p. 139-62, 2000.

WALKER, S. F. Lateralization of functions in the vertebrate brain: a review. British J. Psych., v. 71, p. 329-67, 1980. 